\title{
Tweeting Identity? Ukrainian, Russian, and \#Euromaidan*
}

\author{
September, 2015
}

\begin{abstract}
Why and when do group identities become salient? Existing scholarship has suggested that insecurity and competition over political and economic resources as well as increased perceptions of threat from the out-group tends to increase the salience of ethnic identities. Most of the work on ethnicity, however, is either experimental and deals with how people respond once identity has already been primed, is based on self-reported measures of identity, or driven by election results. In contrast, here we examine events in Ukraine from late 2013 (the beginning of the Euromaidan protests) through the end of 2014 to see if particular moments of heightened political tension led to increased identification as either "Russian" or "Ukrainian" among Ukrainian citizens. In tackling this question, we use a novel methodological approach by testing the hypothesis that those who prefer to use Ukrainian to communicate on Twitter will use Ukrainian (at the expense of Russian) following moments of heightened political awareness and those who prefer to use Russian will do the opposite. Interestingly, our primary finding in is a negative result: we do not find evidence that key political events in the Ukrainian crisis led to a reversion to the language of choice at the aggregate level, which is interesting given how much ink has been spilt on the question of the extent to which Euromaidan reflected an underlying Ukrainian vs. Russian conflict. However, we unexpectedly find that both those who prefer Russian and those who prefer Ukrainian begin using Russian with a greater frequency following the annexation of Crimea, thus contributing a whole new set of puzzles - and a method for exploring these puzzles that can serve as a basis for future research.
\end{abstract}

\section{Keywords: Ukraine, \#Euromaidan, Identity, Protest, Language, Ethnicity, Social Media}

*The data analyzed in this paper were collected by the Social Media and Political Participation Lab at New York University, which is funded in part by the INSPIRE program of the National Science Foundation (Award \# SES-1248077), and New York University's Dean Thomas Carew's Research Investment Fund. 


\section{Introduction}

Why and when do group identities become salient? The extant literature on the means by which ethnicity and other group identities impact conflict (e.g., Fearon \& Laitin 2003), public goods provision (e.g., Habyarimana et al. 2007), and political and voting outcomes (e.g., Chandra 2004) has concluded that the impact of group identities tends to vary in relation to the salience of those identities. That is, ethnicity as such matters for political outcomes only to the extent that it becomes politically salient.

Existing scholarship has suggested that insecurity and competition over political and economic resources as well as increased perceptions of threat from the out-group tends to increase the salience of ethnic identities, as well as that individuals activate identities that allow them to accomplish their personal or social goals (Oakes 1987). This work further suggests that individuals will seek opportunities to activate particularly important identities (Stryker \& Burke 2000). Most of the work on ethnicity, however, is either experimental and deals with how people respond once identity has already been primed, is based on self-reported measures of identity, or is features analysis of election results. Additionally, very little existing work really explores the specific sorts of shocks that may tend to lead to activation of ethnicity as a salient cleavage; the goal of this manuscript is to take a step in that direction.

More specifically, we examine events in Ukraine from late 2013 (the beginning of the Euromaidan protests) through the end of 2014 to see if particular moments of heightened political tension led to increased identification as either "Russian" or "Ukrainian" among Ukrainian citizens. Such a hypothesis should not seem out of line to those who have been observing recent events in Ukraine closely. Much of the early analysis of recent events

in Ukraine has been framed in terms of an ethnolinguistic cleavage (Fisher 2014). Even before more direct involvement from the Russian state, news articles often referred to the 
divisions between "Ukrainians" and "Russians" in Ukraine, or sometimes more specifically between "Ukrainian Speakers" and "Russian Speakers". These accounts are founded on two basic assumptions. The first is that these are the most salient political identities shaping individuals' behavior in Ukraine during this period. The second is that the salience of these identities remained stable throughout the period of protest, as well as into the conflict and crisis period. Our research does not directly test the first of these assumptions, but deals with the second assumption, considering how identity salience may have changed over time.

In tackling this question, we use a novel methodological approach, drawing on new sources of data. In an effort to observe ordinary Ukrainians in a non-laboratory setting, we introduce a new approach to studying the activation of identities through the study of language usage on Twitter in multi-lingual Ukraine. More specifically, we test the hypothesis that those who prefer to use Ukrainian to communicate on Twitter will use Ukrainian (at the expense of Russian) following moments of heightened political awareness, such as the flight of Yanukovych or the annexation of Crimea, and those who prefer to use Russian will do the opposite $\mathrm{L}^{1}$ Additionally, by working with social media data, we are able to observe individuals' behavior under non-research conditions, which provides a significant departure from the work to date. Analysis of social media of course has its own limitations and challenges, but it clearly offers an opportunity to study individual behavior outside of the laboratory in a new and much larger-scale manner.

The stakes for understanding when and why individuals will tend to shift from ethnicity being a less to a more active and salient identity are potentially quite high. Work on ethnic conflict often wrestles with the sometimes puzzlingly swift shifts from generally peaceful interethnic coexistence to violent conflict and even ethnic cleansing. We see this, for example, in cases like the former Yugoslavia, where the importance of ethnicity seemed to shift almost overnight. Understanding broadly that political and economic resource incentives contribute

\footnotetext{
${ }^{1}$ See for example https://foreignpolicy.com/2015/06/26/why-ukrainians-are-speaking-more-ukrainian/
} 
to this activation is essential, but these circumstances exist in numerous cases where ethnicity does not become salient. A more micro-level analysis has the potential to help us disentangle some of the nuances of this complex phenomenon.

To be very clear, our primary finding in this paper is actually a negative result: we do not find evidence that key political events in the Ukrainian crisis led to a reversion to the language of choice at the aggregate level, which of course is extremely interesting given that much ink has been spilt on the question of the extent to which Euromaidan reflected an underlying Ukrainian vs. Russian conflict. Moreover, while one could be tempted to disregard such a result as simply illustrating a shortcoming in our new approach of using social media to study the activation of ethnic identity, we do indeed find one very dramatic break in our data, but one which was not entirely in line with what we were expecting to observe. More specifically, both those who prefer Russian and those who prefer Ukrainian begin using Russian with a greater frequency following the annexation of Crimea, and these findings hold for the remainder of the time period. So with the ability of the method to detect changes in language usage appearing plausible, we believe the negative findings open up a whole new set of interesting puzzles - and a method for exploring these puzzles - that can serve as a basis for future research.

In the following sections we will begin by engaging with the existing literature on ethnic salience, particularly in political science, and develop a set of hypotheses to be tested later in the analysis. We will briefly discuss the Ukrainian case, providing background within which to situate the analysis. Next we outline our novel methodological approach before reporting the results of our analysis. With our null result in hand, we then consider a series of alternative explanations, some technical and some theoretical, for the results we did find.The final section concludes and suggests avenues for future research. 


\section{Ethnicity, Salience and Crisis}

\subsection{Theories of Identity and Why Salience Matters}

The political science literature has featured several approaches to the understanding of group identity. Primordialist approaches treated identities as fixed, and also singular. Individuals had an ethnicity, a national identity, etc., and this identity was not subject to change. These theories were dominant for many years in the social sciences, and as Chandra has argued, are still implicit in many studies of identity (Chandra 2012). On the other hand, constructivist approaches suggest that identities can be fluid and contextual. Chandra further emphasizes that individuals have, at any given moment, multiple identities on which they can choose to draw, and that their choices will depend on a number of factors. She distinguishes in particular between nominal and activated ethnic identities. Nominal ethnic categories include all ethnic identities available to us by virtue of descent, whereas activated ethnic identities are those to which we actively claim membership (Chandra 2012). While Chandra's work is entirely about ethnic identities, a constructivist understanding of ethnicity makes clear the fact that just as an individual may activate various ethnic identities, she may activate various non-ethnic identities as well.

Another contribution of constructivist theories to our understanding of group identity, again explored largely through ethnicity, is that ethnicity as a category is not exogenous to the political processes that it is often said to impact. Horowitz, for example, points out that the processes by which conflict between ethnic groups emerges and the processes by which ethnic identities become important to political processes are not only endogenous, but mutually constitutive (Horowitz 1985). Ethnicities can crystallize in anticipation of conflict or in response to it, cultural norms within ethnic groups can emerge as a response to threat, etc. Others (e.g., Posner 2012, Chandra 2012) have similarly argued that once we acknowledge that ethnicities are not fixed, we must acknowledge that part of what may 
change them are precisely the things that we have hypothesized are caused by ethnicity (unequal provision of public goods, conflict, elections, etc.) In general, however, because much of this work has focussed on changes to the demographic landscape, the assumption is that change is very slow, even if it is endogenous to political processes.

Here our key variable of interest is a shift in the importance of an ethnic identity, or, more precisely, in its activation in response to external shocks. Implicitly, this is in contrast to other types of identities that are not ethnonational. While actually changing one's ethnic or national or linguistic identification may be quite hard, the relative importance of various identities can change much more quickly. The question then is, when do individuals choose to activate certain categories of identity over others?

The stakes for understanding the answer to this questions are quite high. Bhavnani and Miodownik (2009), for example, find that the relationship between ethnic polarization and conflict is moderated by the salience of ethnicity. In other words, where ethnicity is less salient, ethnic diversity is not necessarily a good predictor of conflict. Esteban and Ray develop a model with similar predictions regarding the impact of ethnicity both on conflict and public goods provision (Esteban et al. 2012). This work sheds light on the heterogeneity of findings about the relationship between ethnicity and violence in the literature previously. Understanding what increases the salience of ethnicity gives us important insights into when we should expect ethnic divisions to lead to more conflictual interactions.

\subsection{Theories of Ethnic Salience}

Social identity theory suggests that groups, and individuals' membership in them, play an important role in shaping self-image and in helping individuals to categorize the world around them. As such, individuals will try to increase their self-image by enhancing the group image. Stryker (1968), working from a competing but similar theoretical perspective, argued that individuals have multiple identities, but they will actively seek opportunities to 
enact those that are particularly salient to them. All of this gives us a sense of why our identities are important, and of the importance of salience, but little work in psychology focuses on why certain identities become salient. Oakes (1987) argues that salience is a product of accessibility and fit. This is not dissimilar to Chandra's understanding outlined above. Oakes further asserts, however, that individuals will strategically activate, in a given situation, the identity that best allows them to achieve their personal or social goals. When applied to a more political context, this finding fits in well with much of the political science and sociology work on the subject.

Waters (1999), for example, describes the experience of West Indian immigrants who, upon coming to America, alternately activate identities as "West Indian" or "Black" largely as a function of the instrumental usefulness of the identity in a given situation. When being West Indian will be of economic benefit, they identify this way, whereas when being black is more socially productive, they activate this identity instead.

Posner (2004) moves beyond the consideration of simply ethnic identities, and emphasizes that "individuals posses multiple identities whose salience depends on the context in which the individuals find themselves." His work - and those of others - exploring when people choose to privilege ethnic identifications over other types of potentially politically salient identities suggests that what Waters finds in the case of ethnic identity switching is similar for other identities. Individuals will privilege the identity which increases their utility in a given situation. As such, they will tend to highlight ethnic identification in periods of insecurity or threat which either comes from an out-group, or is perceived to come from or be exacerbated by - an out-group. Bannon et al. (2004) find, for example, that ethnic identities tend to become more politically salient when groups are in competition for scarce economic and political resources, in their case measured by the increased salience of identity close to competitive elections and for people in certain economic sectors. They further find that the process of political mobilization will tend to crystalize or even create ethnic 
identities.

This can be condensed into two key conditions which will tend to lead to increased salience of identity: insecurity and perception of threat (Evans \& Need 2002). These are conditions that have also been highlighted as increasing ethnic polarization. While not framed as increased salience, these concepts are speaking to similar underlying processes, and they transfer well. Under conditions of political or economic insecurity (such as when in competition for political or economic resources), individuals will tend to coalesce around their group identity to try to maximize the benefit of the outcome to the group (and in turn the benefit to themselves as a member of that group). Sometimes, as above, this can relate to competitive elections, but we can also imagine other forms of political and economic insecurity such as the insecurity created by unpredictably changing borders, uncertainty generated by changes in leadership via means other than elections, or insecurity around the intervention of outside forces. These are more similar to the types of insecurity that we see in the case of Ukraine. Perceived threat can be related to actual physical threats of violence on the part of one group against another (which we do see during some periods in Ukraine), but other factors - such as the disagreement over language policy that arose again after the new government came to power in Ukraine - also represent forms of threat.

Posner (2004) finds elsewhere that structural factors incentivizing or deincentivizing cross-group cooperation impact identity salience, focussing particularly on the relative size of the groups as a strong predictor of the salience of identities. Beyond the size of groups, however, it is unclear precisely which structural factors could be important. Some models Caselli \& Coleman 2013) have suggested that factors such as the 'ethnic distance' of groups (that is, how similar or dissimilar they are in terms of culture, physical appearance, language, etc.) would impact the likelihood that ethnicity would lead to conflict, but evidence does not seem, as yet, to support these models.

Others argue that beyond simply perceptions of threat or economic or political uncer- 
tainty, elite framing is important to increasing the salience of ethnicity. This has been, for example, one of the predominant theories of how so much support was mobilized around ethno-national claims in the former Yugoslavia, even in communities where there had been remarkably little conflict on the basis of ethnicity for decades, and even quite high levels of intermarriage and other markers of interethnic cooperation. Toal \& Dahlman (2011), for example, argue that political entrepreneurs were able to play on fears about security by framing the insecurity and instability of political transition in terms of ethnic divisions, and thus promoting and ethnonationalist approach to the conflict. Gagnon (2006) finds similarly that patterns of violence were imposed by elites, and translated to masses by framing threats in ethnic terms. He claims that this was a strategic attempt on the part of elites to maximize the territory and resources that they themselves would control. ? $^{2}$

This literature then provides us with some basic principles to help us develop expectations about when ethnicity will become a salient cleavage. We should expect ethnicity to be more salient when competition between groups for resources (political and economic) is higher and where there is therefore increased insecurity in these areas, as well as during periods of political contention and when perceptions of threat are higher. Potentially, it is critical for there to be an ethnic frame presented on the part of elites, although evidence for this in models which emphasize political competition is not presented, and arguments emphasizing an ethnic frame often suggest that this frame may be sufficient in a period of uncertainty even in the absence of real competition for resources.

What is missing from this literature, however, is an understanding of precisely how the micro-level process of ethnic activation is motivated. The approaches discussed above are macro-level theories of broad trends that should increase ethnic salience. The aim of our manuscript is, instead, to explore whether there are specific types of shocks which will tend to shift the manner in which individuals are engaging with their ethnic identity over the course of

\footnotetext{
${ }^{2}$ See Oberschall (2000) for another example of this perspective.
} 
a political crisis. The emphasis is thus on trying to garner a more micro-level understanding of what prompts a shift in the salience of ethnicity as an identity. Understanding the answer to this question has important implications for explaining why we see ethnic based conflict emerge and relationships between ethnic groups shift, seemingly quite suddenly, and understanding this can serve to add new layers to our understanding of the role that ethnicity plays in politics and in violence.

\subsection{Hypotheses}

From the literature explored in previous sections, we can derive expectations about the types of shocks that we would expect to motivate an increased salience of ethnic identity. In terms of increasing political or economic insecurity or uncertainty, such shocks might include shocks to the legitimacy of the state, shocks to the stability of state boundaries, or sudden changes in political power. In terms of perceptions of threat these include violence, increased expectations of violence, or threats to state boundaries (which have the potential to completely alter the dynamic of power for citizens). Thus:

H1: In response to shocks to the stability and boundaries of the state itself, shocks to the legitimacy or composition of the state and its government, shocks to security and expectations of violence, and/or shocks to levels of/access to political and economic resources, the salience of ethnicity will increase.

Further, if theories emphasizing framing by elites are correct, we should expect this effect to exist exclusively when, or minimally to be greatly amplified by, situations where elites frame such shocks in ethnic terms. Thus:

H2: In the presence of elite framing, the effects of these shocks will be larger.

Alternatively, if simply increased uncertainty motivates the activation of ethnicity as a salient identity is, then rather than responses to individual shocks we might instead see an overall trend of increasing ethnicity salience over the course of the crisis, producing the 
following hypothesis:

H3: Across the entire time period of an ongoing crisis, we should expect increasing salience of ethnic identity

In the following sections we outline our estimation strategy for testing these hypotheses, describe the data and the case used for estimation, and analyze the results of the study.

\section{Recent Events and Ethnicity in Ukraine}

Before discussing the recent events in Ukraine which will serve as the case for testing our theory, it is worthwhile to briefly outline the dynamics of ethnonational identities in Ukraine and their relationship to politics in the past. This will help to establish a foundation for why this case is well-suited to an exploration of factors impacting ethnic identity salience.

\subsection{Ethnic and National Identity in Ukraine}

The relationship between ethnonational groups in Ukraine in the post-Soviet era has been largely peaceful, but with significant political conflict organized around these identities. Barrington \& Herron (2004) cite the situation of ethnic groups in Ukraine as "the dogs that didn't bark" phenomenon, referring to the fact that there are significant ethnic cleavages, but not significant ethnic conflict (at least as defined in terms of violent conflict). Scholars point to the lack of clarity about how to define Ukrainian national identity, as well as the role of elites in promoting conflictual relationships between ethnonational groups. Some of what complicates our understanding of ethnicity in Ukraine is the fact that there are three potentially ethnically relevant cleavages that are used to describe the divisiveness (or lack of divisiveness) in Ukrainian life: ethnicity (or nationality), language and region.

The dynamics of these cleavages are deeply embedded in Ukraine's history. The bound-

aries of empires throughout history have crosscut the country, creating different historical 
experiences. This was further entrenched during the Soviet period, as the Soviet state simultaneously created policies that tended to draw thick lines delineating specific ethnic and national communities and boundaries (sometimes in ways that did not match on the ground realities), while also promoting and emphasizing the Russification of the entirety of Soviet territory. Today, in Ukraine, we see this in the way Ukrainians identify. Most Ukrainians identify as either ethnically Russian or ethnically Ukrainian. According to the 2001 census Ukrainians make up $77.8 \%$ of the population of the country, while Russians make up $17.3 \%$ (other groups are not discussed in our analysis, as the next largest population, Belorussians, makes up less than $1 \%$ of the population). On the other hand, in the same census, nearly $15 \%$ of those identifying as ethnically Ukrainian chose Russian as their native language, and just under $4 \%$ of those identifying as Russian chose Ukrainian as their native language. Thus, boundaries are complex. Scholars do not entirely agree on even the number of ethnic groups to consider in Ukraine, with some suggesting that instead of two groups, we should think of Ukraine in terms of three groups: Ukrainian speaking Ukrainians, Russian speaking Ukrainians, and ethnic Russians (Arel 1995; Wilson 2002).

Scholarship on the question of language and ethnicity in the country, however, suggests that while this fluidity is apparent, linguistic identities are, rather than representations of the most spoken language in daily life, in fact politically important assertions of identity with a community. In other words, linguistic identities are often markers of ethnic identification. Arel (2002) concludes that language identity is "about who you are, not what you speak" (238). Some of this is also connected to histories of the Soviet census and some general lack of clarity about the political meaning of census questions. Similar to Arel, Kulyk (2006) finds that people view identifcation of "native" language, as being about either their language of thinking, their national identity or the language of their parents, rather than about the way they actually communicate in the world. Besides the historical context, the idea of native language may be driven in part by the fact that most Ukrainians (of both ethnicities) 
are at least passively, and often actively, bilingual, (Ivanova 2013), and therefore actually have access to both linguistic categories for identity in most cases. Under these conditions, then, they pick the linguistic identity which best maps to their ethnic and political identity, regardless of the status of daily use.

Importantly, these linguistic identities can map onto political issues (although their salience has varied over time). Recent surveys conducted by Timothy Frye (Frye 2014) find that while the actual ethnic and linguistic identity of a candidate had no effect on voters' willingness to support them, Ukrainian speakers and Russian speakers had significantly different preferences over policy. This suggests a lack of ethnic discrimination, but accompanied by clear ethnic differentiation in politics. Further, because it is typically the case that politicians' preferences map onto these ethnic preferences (that is, ethnically Russian candidates promote a set of policies that ethnic Russians prefer), de facto voting is likely to break down along ethnic and linguistic lines. In work exploring preferences immediately preceding the Orange Revolution in 2004, Constant and co-authors found similar associations between ethnic and linguistic identities (which mapped similarly) and political preferences. (Constant

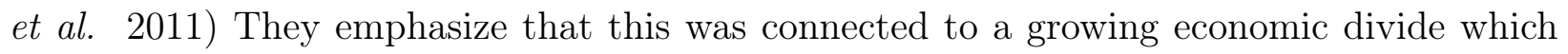
favored Russian speakers (as a linguistic community), and which the elites in the Orange Revolution were partially seeking to undermine (Constant et al. 2012).

The final consideration in the politics of identity in Ukraine is the fact that in addition to ethnic and linguistic identities (which as we have suggested above tend to map onto one another closely, though not exactly), there is a regional divide which is highly correlated with these other identities. Indeed, one of the challenges in disaggregating these identities is the fact that there is a high degree of overlap between regional and ethnic and linguistic identities. Barrington and Herron find evidence to support the fact that these regional divisions persist even once they account for ethnic and linguistic identities (Barrington \& Herron 2004). For both technical and theoretical reasons, we will not consider the regional 
aspect of identity actively in this manuscript, but it is important to keep in perspective the fact that it does represent an additional and potentially competing cleavage in Ukrainian society.

\subsection{The EuroMaidan Protests, Crimea and the Crisis in the East}

The particular case explored in this paper centers on the recent political upheaval which happened in Ukraine in 2013-2014. The unrest began with large-scale protests in Kyiv that broke out in response to then president Viktor Yanukovych's decision not to sign an association agreement with the European Union, and instead to pursue closer ties with Russia and to join Russia's proposed economic union between former Soviet states. The protests were the largest in recent Ukrainian history, and although the movement was originally nonviolent, violent confrontations between police and protestors eventually took place resulting in multiple deaths and hundreds of injuries. Protests continued through February, becoming increasingly violent. Eventually, in the end of February, President Yanukovych was forced to flee the country to Russia, and an interim government composed of opposition leaders took power.

Almost concurrently with the change in government, Crimea, a small region in the SouthEast of the country which has a particularly large concentration of Russian speakers, began to

make moves towards secession. On February 27th, armed gunmen seized control of regional government buildings in Crimea, and on March 1st pro-Russian troops had gained control of the peninsula. While there was initially some debate, it is now clear that at least some of the troops involved in these events were under Russian command. In March, in a referendum whose legitimacy is in question internationally, Crimea voted to join Russia, and by the end of March Ukrainian troops were forced to leave Crimea and cede the territory to the Russian Federation.

During March and April unrest, and eventually separatist violence, began to increase in 
the Eastern regions of the country as well. Unlike Crimea which has a clear Russian-speaking majority, ethnic and linguistic populations in the East are more heterogeneous, and while reports suggest that there are certainly Russian military personal and equipment deployed to support these movements, Russia was much more reluctant to vocally support them early on. The situation in the Eastern part of the country remains tense, with neither side able to fully assert control of the area.

The role that ethnolinguistic cleavages have played in this conflict is unclear and existing accounts conflict. The initial protests were not ethnic in nature, and for the most part were not framed as such, even by elites, domestically. It was not until the protests succeeded in overthrowing the government that ethnic frames became more common. Nonetheless, the media centered many of their discussions around existing cleavages between Russian and Ukrainian speakers in Ukraine, and around the regional divide, although local actors worked to distance themselves from this framing. Once the government was overthrown, however, ethnic frames became more prominent. Russian speaking elites expressed fear about the marginalization of the Russian language under the new government. Russia encouraged a narrative of the oppression of their coethnics abroad particularly once the government was overthrown, and in the situations in Crimea and the East. The narrative shifted from one centered on a European future for Ukraine (which while differentially supported across linguistic and ethnic groups is not an inherently ethnic issue), to one centered around the protection of Russian identity, or on the other side, the unity of Ukraine.

These factors together make Ukraine an excellent case for exploring the way that particular shocks impact ethnic salience. Over the time period under consideration we have a variety of types of shocks, differences in the framing of the conflict, and both protest and conflict which we can consider. In the following section we outline the data and empirical strategies we use to test our hypotheses. 


\section{Data and Estimation Strategy}

\subsection{Advantages and Disadvantages of Social Media Data}

Given that social media data is central to our paper, it is worth taking a few moments to outline the advantages such data provide for this type of work, as well as to acknowledge shortcomings. What social media allows us, as researchers, to do is to observe individual behaviors outside of an experimental setting in a way that has never before been possible. For social media users, we observe aspects of their opinion formation process, their social networks, and their behavioral choices which would never have been possible to study on such a large scale using other types of data. In other words, we can take our questions about individual behavior to the data, and find some quantifiable evidence to support or refute our hypotheses. Particularly in cases where social media is widely used, and even plays an important role, in mobilizational processes, as is the case in Ukraine, this is a particularly fruitful source of data.

In Ukraine, social media use has been steadily increasing in the last several years. vKontakte, a Russian social media website similar to Facebook was, in 2013, the second most visited website in the country after Google. With regards to politics, however, Twitter and Facebook have tended to play a more important role, with Facebook representing the most common source from which Ukrainians accessed independent media sources in 2013 (Minchenko 2013). Over the course of the protests, Twitter in particular became increasingly widely used. In fact, recent estimates by Yandex suggested that from July 2013 to July 2014 the number of Twitter users in the country more than doubled. They suggest that this increase is largely political, as all the most common hashtags during that period were related to political events. Internet penetration is estimated at just under $42 \%$, but the internet has a history of being used for political purposes beginning with the Orange

Revolution and up to the present day (Sikorska 2014; Bohdanova 2014). This developments 
make this particular case a particularly fruitful one to examine using social media data.

Obviously, one of the key limitations is that we are looking only at a subset of individuals, and it is a subset which will tend to be younger, better educated, and wealthier than the general population. This is problematic for inference to the general population in that we need to think carefully about the interpretation of our results. Secondly, social media data only allows us to observe people's public behavior, and we know that much of what is happening related to the social science questions we are interested in is likely not happening in public (even some of the Twitter activity may be private). Nonetheless, the behavior that we are able to observe, on the scale on which we are able to observe it, is still significantly more than is available through other data sources. For the question at hand, social media allows us to go beyond self-report and primed experiments, to explore actual changes in individual behavior over time. Obviously, this does not take the place of other types of data, but provides an exciting new source of information for researchers.

\subsection{Data}

The data used in this paper is a dataset of tweets collected in real time over the course of the Ukrainian protests and ensuing crisis. Beginning on November 25th, the Social Media and Political Participation Lab (SMaPP) at New York University began to collect all tweets sent using a collection of key words and hashtags $3^{3}$ These collection criteria were selected to try to maximize coverage of all twitter activity relevant to the events on the ground.

The theory tested here is about when the salience of ethnolinguistic cleavages will increase, particularly which types of events on the ground will lead to an increasing salience of this cleavage. As such, it was critical to narrow this larger data set down to a data set

\footnotetext{
${ }^{3} \mathrm{~A}$ list of hashtags and key words used to generate the tweet collection is presented in Table A.2 in the appendix, along with the date when they were added when available. The data was collected in real time using the Twitter Streaming API. During the early period of collection, dates that terms were added to the collection addition were unfortunately not tracked, so keywords and hashtags without dates represent early additions to the collection.
} 
which we felt confident included only individuals from Ukraine. The first step in this process was to create a data set of all geolocated tweets sent from within the boundaries of Ukraine (including Crimea). This produced a dataset of 91,910 tweets. Although this is a significant amount of data, our estimation strategy relies on sufficient data in tight time periods of the protest, which means that relying on only the geocoded tweets would not provide sufficient data; we also would be needlessly discarding data that is probably germane to our analysis.

Thus we rely as well on a second way to potentially identify a user's location, which is through the user entered location field in the user "biography". The biography is a part of each Twitter user's profile, and users have the option to manually enter their location. While there is of course lots of noise here - location data is optional and there is no verification process - many do in fact enter legitimate locations. We therefore used a python script to iterate over all the tweets in our collection to identify all tweets where the user's location field contained the word Ukraine or the name of any Ukrainian city with a population greater than 50,000. This produced an additional 4,816,313 tweets. One potential concern with our data might be that it is geographically biased, particularly that it might include insufficient activity from eastern Ukraine. While mapping the manually entered location field is inexact and somewhat cumbersome, Figure 1 (below) maps all the geolocated tweets in our collection. We can see that geographic distribution is spread throughout the country, including the east and Crimea. There are focal points in urban areas, which is not surprising, but activity is not limited to a single region or a single city, but is instead broadly distributed throughout the country. 


\section{Map of Geolocated Tweets}

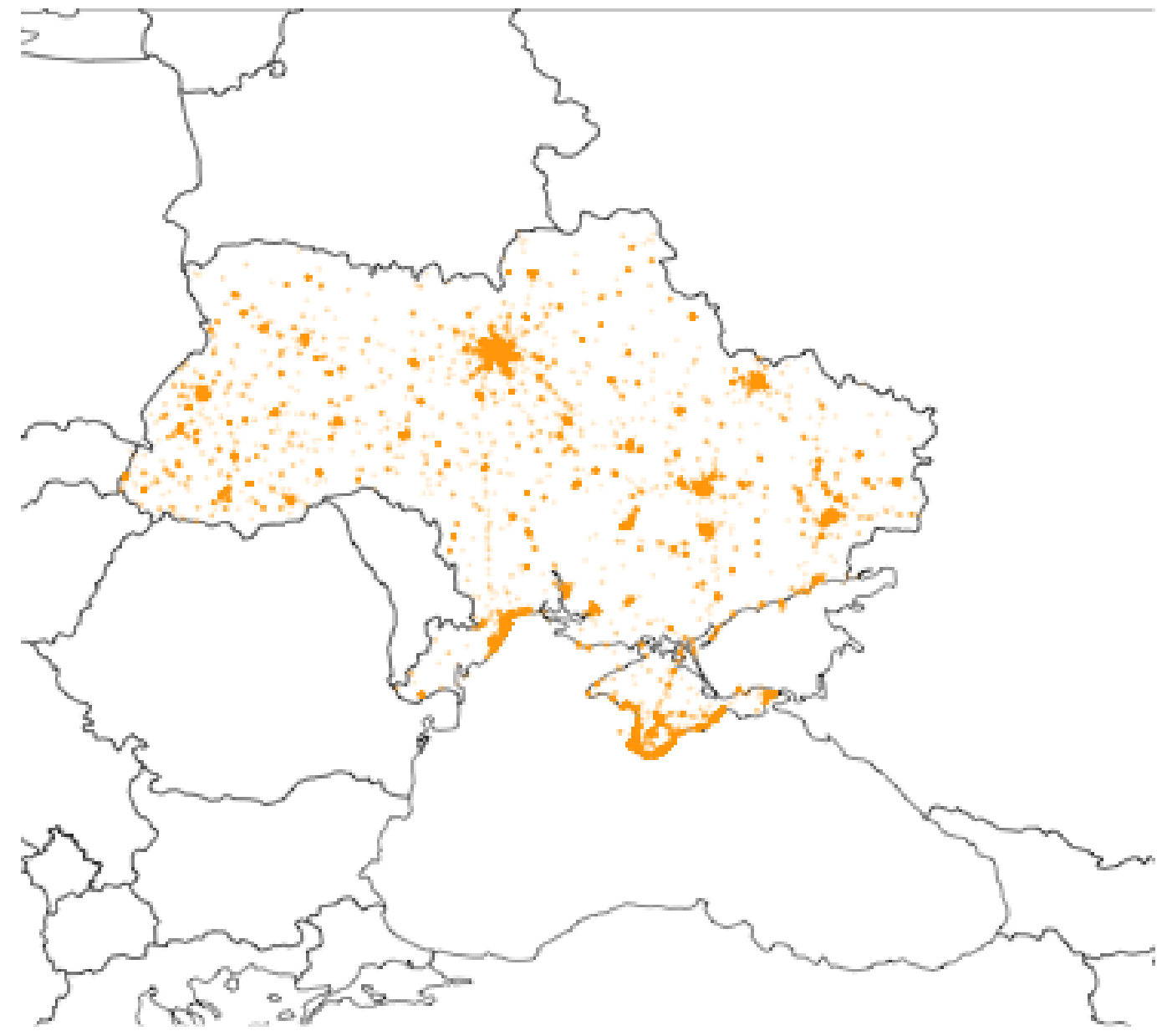

Figure 1: Map of the location from which tweets in our dataset which contain geolocation data were sent. Darker colors indicate a greater density of tweets sent over the research period. 
Next, we filtered out all tweets that were not in Russian or Ukrainian 4 Russian, Ukrainian and English are by far the most common languages in our dataset. Table 1 below shows the number and proportion of tweets in our dataset by language. As we can see, Russian is the most common, constituting about $50 \%$ of the total dataset. Ukrainian and English each represent about 20\%, and all other languages combined constitute only $5.4 \%$. For $3.2 \%$ of tweets, Twitter was unable to automatically classify their language ${ }^{5}$

Number and Percentage of Tweets by Language

\begin{tabular}{|l|l|l|}
\hline Language & Number of Tweets & Percentage of Tweets \\
\hline Russian & 2446465 & $50.8 \%$ \\
\hline English & 997955 & $20.7 \%$ \\
\hline Ukrainian & 958282 & $19.9 \%$ \\
\hline All Other Languages & 260966 & $5.4 \%$ \\
\hline Unidentified & 152645 & $3.2 \%$ \\
\hline
\end{tabular}

Table 1: Number of tweets sent per language in our dataset along with the percentage of total tweets that that language accounts for. All languages comprising less than $1 \%$ of tweets individually are listed together. Unidentified tweets are tweets where Twitter was unable to automatically detect the language. This is typically due to insufficient linguistic information in the tweet (for example if the tweet is only a link or image).

After some final cleaning of the data, this left us with a dataset of tweets sent between November 25th, 2013 and September 30, 2014, in either Russian or Ukrainian, from users we are confident with a relatively high degree of certainty are in Ukraine, who have chosen their user language as either Russian or Ukrainian. This final, cleaned dataset contains 3,008,079 unique tweets. Notably, in many cases several of these tweets will come from multiple users. Table 2 below shows the quintile distribution of the number of tweets sent per user. As we can see, it is not until the third quintile that the mean or media number of tweets sent is

\footnotetext{
${ }^{4}$ This is not to say that the choice to use other languages - especially English, a more efficient way to attract the attention of international news media - is not interesting unto itself, but as our primary interest here is to explore the use of Russia and Ukrainian, tweets in other languages serve only to enter noise into the analysis. We have address the use English tweets during the Euromaidan protests elsewhere; interested readers should see (self-citations omitted).

${ }^{5}$ In previous research, undeclared tweets were most often links or other types of posts lacking sufficient linguistic information for Twitter to analyze
} 
greater than one. In fact, the median number of tweets per user in our dataset is only 2 . Only $3.3 \%$ of users tweeted more than 100 times in the dataset. ${ }^{6}$

\section{Distribution of Tweets Per User by Quintile}

\begin{tabular}{|l|l|l|l|}
\hline Quintile & Upper Bound & Mean & Median \\
\hline First Quintile & 1 & 1 & 1 \\
\hline Second Quintile & 1 & 1 & 1 \\
\hline Third Quintile & 3 & 2.4 & 2 \\
\hline Fourth Quintile & 10 & 6.1 & 6 \\
\hline Fifth Quintile & 56959 & 151.7 & 30 \\
\hline
\end{tabular}

Table 2: This table shows the mean and median number of tweets per user sent for each quintile of the distribution in our dataset.

\subsection{Operationalizing Ethnolinguistic Identity}

As discussed previously, the fact that research suggests that the identification of a dominant language in Ukraine often serves as a marker of identity, and that these identities correspond largely (though not precisely) to ethnic identities. In attempting to identify ethnolinguistic identity in social media data, we use the language that users self-select when they join Twitter. When initially registering, users are required to select a language, and since 2012 both Ukrainian and Russian have been available. We limit our dataset to users who have selected Ukrainian or Russian as their Twitter language. 7

Given the relationship between dominant language and ethnonational identity discussed above, this would seem to represent a reasonable proxy for these identities. That said, there are several reasons why users who are ethnically Ukrainian might choose Russian as their

\footnotetext{
${ }^{6}$ Please note that we count retweets as unique observations, so while each of these observations represents a distinct instance of an individual sending a tweet, text may in fact be duplicated in some cases. Later in this section we show that our results are robust to eliminating retweets. Moreover, in Section 5.3 we consider the possibility that some of these tweets were made by "bots", or automated Twitter accounts, and again show that our findings are largely unchanged by removing accounts that display characteristics associated with being a bot.

${ }^{7}$ Again, this is not to say it would not be interesting to try to figure out what non-Ukrainian and nonRussian speaker in Ukraine were saying about the developing crisis and conflict, but these users are not germane to the current study.
} 
language. The first is if they joined Twitter before Ukrainian was available, and due to intertia never changed their operating language. Ukrainian was added as a Twitter language on July 5th, 2012. We might, therefore, expect that many Ukrainians who joined before this time would have selected Russian as their operating Twitter language. It is, however, possible to change one's operating Twitter language, and it seems that many in our dataset did that. We find that the distribution of user creation dates for Russian and Ukrainian users is relatively similar - as we can see in Figures 2 and 3 below - which suggests that many Ukrainians initially chose a different language and switched when Ukrainian became available. 8

\footnotetext{
${ }^{8}$ To be clear, every account with Ukrainian as a preferred language that was created before July 5, 2012, must have at some point changed their preferred language to Ukrainian, because the option was not available at the time of account creation.
} 


\section{Distribution of User Creation Dates Russian Users}

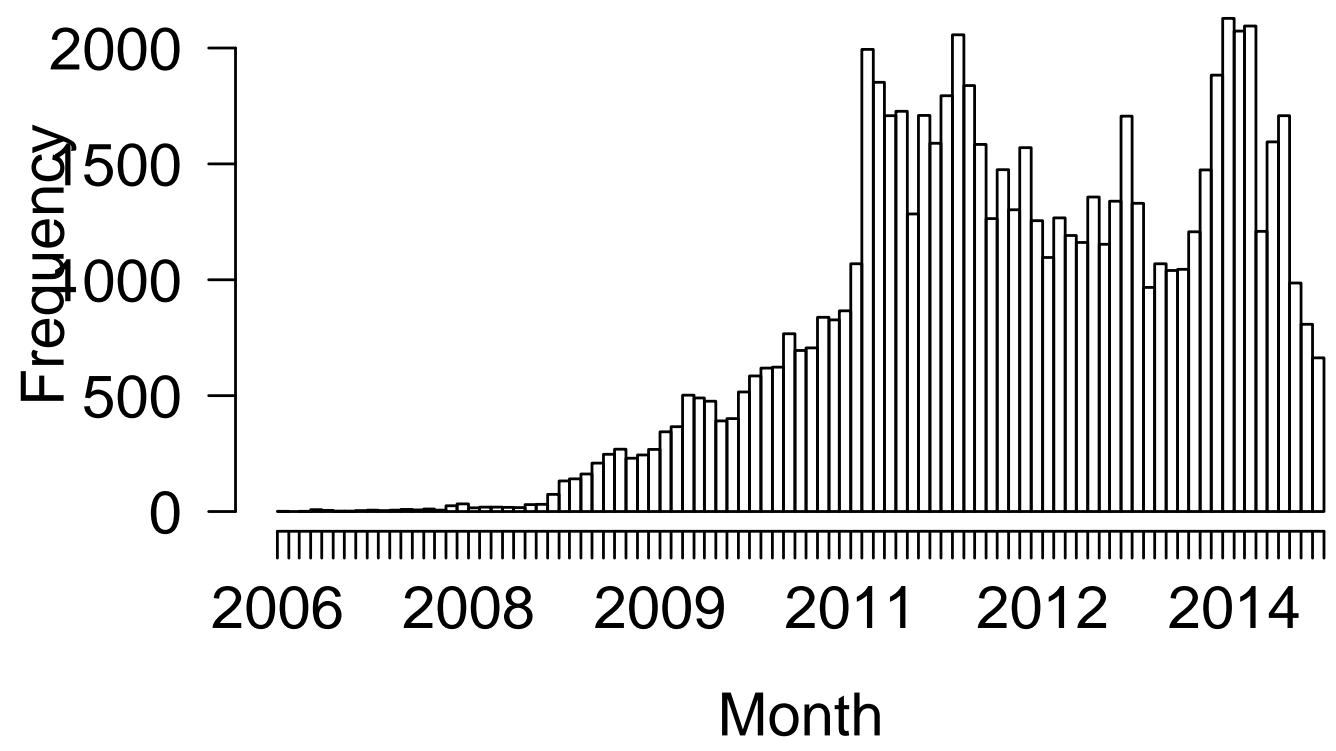

Figure 2: This figure shows the distribution of the months in which users initially created their Twitter accounts for Russian users in our dataset. 


\section{Distribution of User Creation Dates Ukrainian Users}

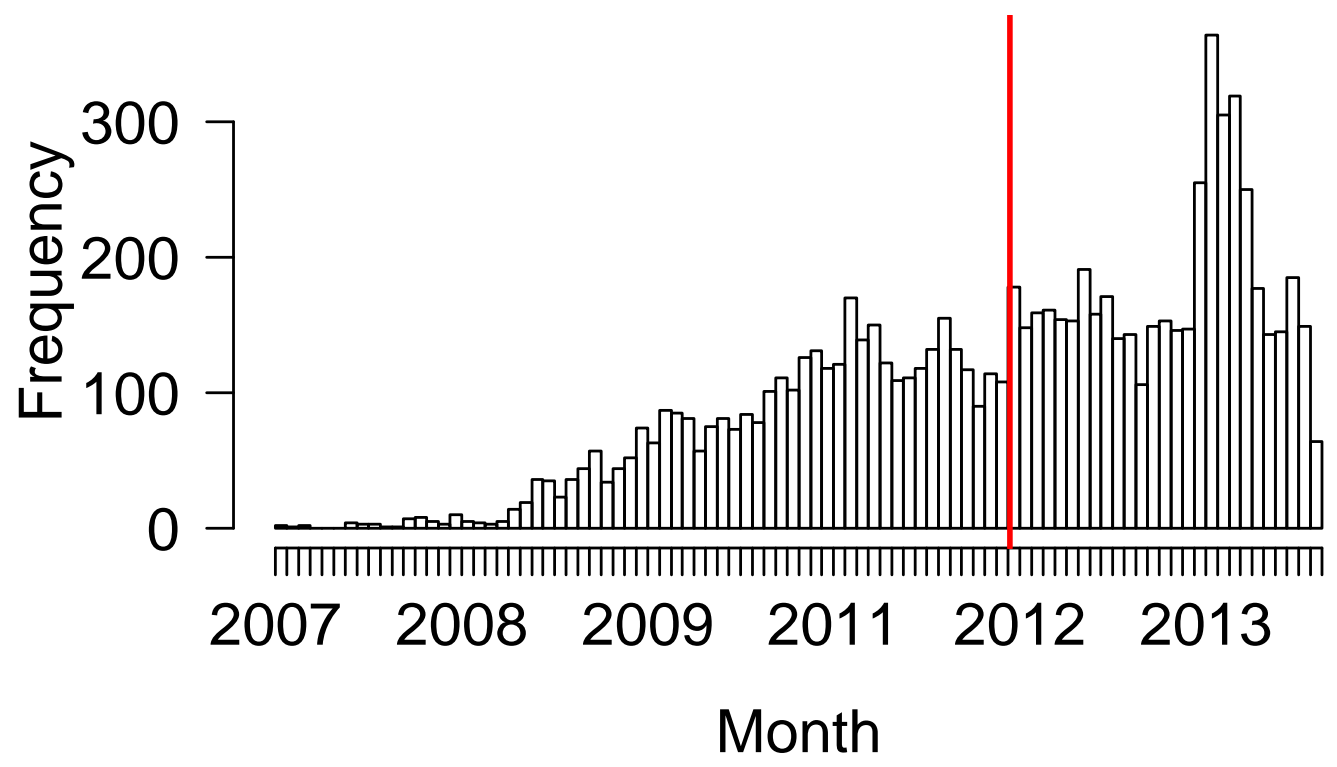

Figure 3: This figure shows the distribution of the months in which users initially created their Twitter accounts for Ukrainian users in our dataset. The red line indicates the date on which Ukrainian became an available language for Twitter accounts. This means that all accounts to the left of that red line represent users who changed their language to Ukrainian from a different language after July 5, 2012, thus demonstrating that not all users keep their original preferred Twitter language out of inertia. 
Second, Wilson (2014) has argued that there is a greater technical capacity for users in Russian and that therefore there might be technological reasons why users would select Russian over Ukrainian, particularly given the largely bilingual nature of the country. Further, some proportion of users may select Russian as their language despite identifying as ethnically Ukrainian, although the literature cited above suggests that this should be a minority. Our data certainly suggests that many Ukrainians are selecting Russian, as only $17 \%$ of users in the dataset select Ukrainian as their preferred language, essentially a reversal of the proportions in the population. Another possibility is that despite our attempts to limit the dataset to Ukraine, we are capturing some users tweeting from within Russia. Finally, it is possible that some ethnic Ukrainians are choosing English as their Twitter language and are therefore excluded from our dataset.

This is potentially problematic for inference, and for our use of this measure as a proxy. If people living in Ukraine are indeed selecting Russian as their preferred Twitter language for reasons independent of their own identity, then it makes our "Russian-preferred" measure noisy. On the other hand, while we may have reasons to believe that ethnic Ukrainians are choosing Russian as their language for a variety of technical and other reasons, we have no such reason to believe that those who identify as ethnically Russian would select Ukrainian as their language (except possibly for the small minority of people who identify as ethnically Russian but with Ukrainian as their first language). Thus, while we may have some doubts about the validity of our group of Russian users, we can be more confident about the validity of the group of Ukrainian users. Since we segregate our analysis by language group, we proceed with this data with the caveat that results for the Ukrainian sub-group should be taken as more definitive than results for the Russian subgroup. As we will see below, our conclusions are largely similar across language groups, but nonetheless a conservative reading of this paper would focus on the results for Ukrainian language users.

Another important note is that our data does not (and cannot) capture people with 
multiple identities $9^{9}$ Most notably, we may missidentify Ukrainians who identify primarily as Russian ethnically, but speak Ukrainian as a first language. Of course, however, it is possible to come from a mixed family, or to be from a Russian family but to have a strong civic identity as a Ukrainian and therefore have a mixed identity, or any number of other more complicate scenarios. By necessity, our measure forces a categorization of individuals into one or the other identity. It is therefore perhaps best to think of this as an operationalization of an individual's dominant identity. When forced to make a choice, this is what they choose. 10

\subsection{Operationalizing Increased Salience}

While users select a language when they join Twitter, they are not constrained in terms of the language in which they post (or "Tweet"). Users can tweet in any language, and they can change that language with any tweet. Fortunately, computer scientists have gotten quite good at identifying language from text, and tweets today contain Twitter's own coding of the language of the tweet as part of the metadata.

We suggest that one observable manifestation of the increased salience of ethnic identity should be users tweeting more frequently in their their dominant language, both as a costly signal of their identity and as a device for communication with the in-group. In other words, as ethnicity becomes more salient, users identified as Ukrainian should use more Ukrainian and users identified as Russian should use more Russian. We operationalize this by considering the proportion of tweets sent by Russian users in Russian and Ukrainian users in Ukrainian, with the expectation that in response to particular types of events, we

\footnotetext{
${ }^{9}$ One component of this is that many people in Ukraine use what is reffered to as "Surzhyk", which is a mix of Russian and Ukrainian. Exact definitions of what constitutes Surzhyk vary, and our identification process for languages here cannot isolate it from Russian or Ukrainian, but a deeper exploration of the impact of Surzhyk on our analysis could be interesting moving forward.

${ }^{10}$ Again, it is worth noting that this is an actual real-world choice that individuals make in the course of their own lives - not one made in a laboratory or during a survey by a researcher - that we are able to observe due to the fact that people have made their Twitter data publically available.
} 
should see Ukrainian users tweeting more dominantly in Ukrainian and Russian users more dominantly in Russian. This is obviously only a proxy for ethnicity salience, and not a perfect measure, however given the dynamics of language and identity in Ukraine it is a reasonable proxy for the way individuals might express shifts in ethnic salience.

\subsection{Estimation Strategy}

Above, we suggested that we should expect the salience of ethnic identity to increase in response to four specific types of shocks: shocks to the stability and boundaries of the state, shocks to the legitimacy of the state and its government, shocks to security and/or expectations of violence and shocks to levels of/access to political and economic resources. Framing theories suggest that without ethnic framing, these shocks should not have much of an effect, or, at the very least, that their impact should be reduced. In contrast, if the key factor in activating ethnicity as a salient identity is simply instability combined with ethnic diversity, we should expect to observe a continually increasing salience of ethnic identities throughout the crisis period (and thus over the entirety of our data collection).

To test these predictions, we therefore model several key events in the Ukrainian crisis as shocks to combinations of these factors. In order to measure the impact of these events on trends in our measure of ethnic identity salience, we use interrupted time series analysis, also called intervention analysis, which is described in more detail below. Briefly, this technique, as illustrated by Box \& Tiao (1975), is designed to measure the impact of particular events on time series trends, while taking into account the particular features inherent to time series data (such as serial correlation) which tend to make estimation techniques which assume independence of events unsuitable 11

The table below outlines the shocks explored in this paper, and the particular political

\footnotetext{
${ }^{11}$ The method has been used to measure the impact of policy interventions on outcomes, and can also be used to measure changes in economic trends in response to external events (Box \& Tiao 1975).
} 
processes they affect, as well as whether ethnic framing was widespread at the time they occurred. Briefly, the events modeled are the first deaths that occurred during the protests, the fleeing of Yanukovych and the beginning of the Crimean secessionist movement, the secession of Crimea and its annexation by Russia, the declaration in Eastern Ukraine of the Donetsk People's Republic, which represented a critical development in the East Ukrainian separatist movements, and the downing of Malaysian Airlines Flight 17 by separatists in the East of the country. These shocks were selected because of their salience in the media, based on interviews with individuals in Kyiv in the summer of 2014 that suggested that these were particularly startling and perspective-shifting events, and in an attempt to model events that represented shocks to the variety of the factors anticipated to be relevant in a variety of combinations.

A few comments on these shocks warranted. First, ideally our analysis would include the first day of violence during the protests, but because this event occurs so early in our dataset, there is insufficient data for our estimation strategy to be effective. This shock is marked on the figures below (the first red line chronologically) to provide context, but is not included in the statistical analysis. Second, it would be ideal to be able to separate the impact of the turnover of power when Yanukovych fled Ukraine and the beginning of secessionist violence in Crimea and to explore the differential effect of these events. Unfortunately, these events were functionally concurrent, and therefore neatly separating them in our analysis is impossible.

In the following section we discuss the estimation strategy in more detail and outline the precise model estimated.

\subsection{Intervention Analysis}

The structure of an intervention model takes the basic form:

$$
Y_{t}=f(I)+N_{t}
$$


Table 3: Shocks Included in Analysis

\begin{tabular}{|c|l|c|c|c|c|c|}
\hline Shock & Date & Security & Legitimacy & Boundaries & Resources & Framing \\
\hline First Protest Death & January 22, 2014 & Yes & Yes & No & No & No \\
\hline $\begin{array}{c}\text { Yanukovych Flees/ } \\
\text { Crimean Crisis }\end{array}$ & February 22, 2014 & Yes & Yes & Yes & Yes & Yes \\
\hline $\begin{array}{c}\text { Crimean } \\
\text { Secession }\end{array}$ & March 16, 2014 & Yes & No & Yes & Yes & Yes \\
\hline $\begin{array}{c}\text { Donetsk People's } \\
\text { Republic }\end{array}$ & April 7, 2014 & Yes & No & Yes & Yes & Yes \\
\hline $\begin{array}{c}\text { Malaysian } \\
\text { Airlines }\end{array}$ & July 17, 2014 & Yes & No & No & No & Yes \\
\hline
\end{tabular}

Where $N_{t}$ represents an ARIMA process used to model the underlying trends in our data, and $f(I)$ is a function modeling an intervention which disrupts the trend. ARIMA models are used in time series analysis both for better understanding of the trends themselves, and most importantly for the process here, for prediction of future outcomes. An ARIMA process explicitly models factors such as autocorrelation and serially correlated errors in order to properly analyze time trends. Functionally, intervention analysis estimates an ARIMA model based on the time series preceding the intervention. The resulting coefficients then estimate the difference between the values that would be predicted from this model for the period following the intervention and those observed in the actual data.

This approach has several advantages for understanding the problem at hand. First, it allows us to take into account the sort of trends that make analysis of time series data inherently challenging (such as the clear lack of independence of observations from one day to the next). ARIMA allows us to model these underlying trends to get a clearer picture of where we see real shifts in outcomes. While of course there are short term variations in behavior over the time period under consideration, by looking at the persistent effect of shocks over time, we can see whether there are sustained changes in behavior. In other words, we can identify real variation as opposed to simply minor, temporary spikes which might be attributed to, for example, a sudden increase in the number of tweets by one influential user on a given day. 
In modeling $f\left(I_{t}\right)$ we use a transfer function, which allows us to model the impact of the intervention on future values of $Y$. In its most basic form, a transfer function takes the form of:

$$
f\left(I_{t}\right)=\omega\left(I_{t}\right)
$$

Where $I_{t}$ is a dummy variable that marks the intervention. This can be modeled either as a pulse function where $I=1$ at time $T$ and 0 otherwise, or as a step function where $I=1$ for all $t \geq T$. In the first case we are modeling an impact at time $\mathrm{T}$ which decays over time, and in the second we are modeling a sustained impact. The particular way that decay is accounted for depends on the way that we structure the transfer function. As we are interested in immediate and persisting results of shocks, here we use the basic transfer function presented above with a step variable. This models an immediate and sustained effect from our interventions ${ }^{12}$

\section{7 $\quad$ Statistical Models}

To estimate the effect of each of the shocks under consideration, we create a model with multiple interventions, one for each of our shocks. We aggregate the data by hour separately for users with Russian and Ukrainian as their preferred Twitter language. Thus, there are two datasets - one containing Russian-preferred users one containing Ukrainian-preferred users - with each dataset containing an observation of the proportion of tweets in the dominant language for each hour of the time period 13

\footnotetext{
${ }^{12}$ As a robustness test, we also ran the model using a transfer function which would allow for gradually increasing effects, and there were not substantive differences in the results. While some significance levels were different from this specification, none of the key findings were altered.

${ }^{13}$ As a robustness check, we also estimated these models using data aggregated at the daily level. This approach is less noisy than the hourly data, but also provides fewer data points on which to estimate the model. Results are again substantively similar; although the significance of some coefficients change, directionality and overall interpretation are identical. For additional robustness checks, and also to alay concerns about stationarity of the series before each shock, we also estimated separate models on truncated time series, with data aggregated by hour, and for each shock subsetted from the overall data set using non-overlapping date ranges. The findings of these analyses are largely in accord with the findings of the model presented in text. While significance levels differ for some shocks, our overall interpretation of the
} 
For each dataset, we then select the ARIMA model (in this case, because none of the series are integrated, this is an ARMA model) which properly models the data. For intervention analysis, the proper way to proceed with model selection is by selecting for the data from the period before the intervention. We want a model that addresses serial correlation of observations and errors as well as stationarity concerns before the intervention, but precisely what we are measuring in looking at the effect of an intervention is a shock to the stationarity of the time series. Before continuing with model selection, we run Dicky-Fuller and KPSS tests for stationarity for the period preceding intervention. For intervention models, we are predicting a lack of stationarity around the intervention, and so stationarity tests focus on the pre-intervention data. The results of these tests are reported in detail in Table 4, but none of the results suggested that the data lack stationarity before the interventions.

\section{Results of Stationarity Tests}

\begin{tabular}{|l|l|l|l|}
\hline Test & Null Hypothesis & p-value & Conclusion \\
\hline $\begin{array}{l}\text { Augmented Dicky-Fuller } \\
\text { (Ukrainian Users) }\end{array}$ & Data has unit root & $<.01$ & Reject null hypothesis of unit root \\
\hline $\begin{array}{l}\text { Augmented Dicky-Fuller } \\
\text { (Russian Users) }\end{array}$ & Data has unit root & $<.01$ & Reject null hypothesis of unit root \\
\hline $\begin{array}{l}\text { KPSS Test } \\
\text { (Ukrainian Users) }\end{array}$ & $\begin{array}{l}\text { Data exhibits level } \\
\text { stationarity }\end{array}$ & $>0.1$ & Fail to reject null hypothesis of stationarity \\
\hline $\begin{array}{l}\text { KPSS Test } \\
\text { (Russian Users) }\end{array}$ & $\begin{array}{l}\text { Data exhibits level } \\
\text { stationarity }\end{array}$ & $>0.1$ & Fail to reject null hypothesis of stationarity \\
\hline
\end{tabular}

Table 4: This table displays the null hypotheses, results and conclusions of both Dicky-Fuller and KPSS tests for stationarity for the pre-intervention data for both Ukrainian and Russian users.

We then use the EACF model developed by Tsay and Tiao (Tsay \& Tiao 1984) to select the appropriate AR and MA models for the data. The following are the resulting models. In the Ukrainian case, our model is ARIMA $(3,0,0)$ and in the Russian case ARIMA $(1,0,1)$.

findings, and most importantly the directionality of effects, is unchanged. 
Ukrainian Users: $Y_{t}=\omega_{1} S_{1 t}^{T}+\omega_{2} S_{2 t}^{T}+\omega_{3} S_{3 t}^{T}+\omega_{4} S_{4 t}^{T}+\omega_{5} S_{5 t}^{T}+\phi_{1} Y_{t-1}+\phi_{2} Y_{t-2}+\phi_{3} Y_{t-3}+e_{t}$

Russian Users: $Y_{t}=\omega S_{t}^{T}+\omega_{2} S_{2 t}^{T}+\omega_{3} S_{3 t}^{T}+\omega_{4} S_{4 t}^{T}+\omega_{5} S_{5 t}^{T}+\phi_{1} Y_{t-1}+e_{t}-\theta_{1} e_{t-1}$

\subsection{Expectations}

The table below outlines what we would expect if the hypotheses outlined above were confirmed, in terms of significance on the coefficients that we estimate and the overall time trends. Generally, we should expect the coefficient $\omega$ to be statistically significant following all shocks (H1). We should expect the size of the coefficient to be largest for the shocks of Yanukovych's Resignation and the beginning of Crimea, as they are the only shocks where all the factors we suspect will increase ethnicity salience are present. If framing theories are correct, we should expect the size of the coefficient to be the smallest for the first shock, as it is the one where ethnic framing is absent (H2). If theories that highlight overall uncertainty are correct, we should also expect that the overall trend will be towards increasing ethnic salience over time, but should suspect that the individual shocks will be insignificant or smaller in size $(\mathrm{H} 3) \cdot{ }^{14}$

Table 5: Empirical Expectations

\begin{tabular}{|l|l|}
\hline Hypothesis 1 & $\begin{array}{l}\omega>0 \text { for all shocks } \\
\omega \text { largest for Yanukovych/Crimea } \\
\omega \text { smallest for Malaysian Airlines }\end{array}$ \\
\hline Hypothesis 2 & $\begin{array}{l}\omega \text { smallest for First Death } \\
\omega>0 \text { for all other shocks }\end{array}$ \\
\hline Hypothesis 3 3 not significant for shocks \\
\begin{tabular}{l}
$\omega$ Regression of overall trend shows consistent growth in ethnic salience \\
\hline
\end{tabular}
\end{tabular}

\footnotetext{
${ }^{14} \mathrm{We}$ are treating the proportion of tweets in a given language as a sign of ethnic activiation, and assuming it means that a higher proportion of the group we are following has chosen to tweet in that language. Given that we are using aggregate data, it may be that a different set of people begin choose to tweet after the observed shocks. In future research this will be pursued with analysis at the individual level, but for now we are skeptical that such a development could explain our findings for reasons we discuss below in Section 5.4
} 


\section{$5 \quad$ Results and Analysis}

\subsection{Results}

Figures 4 and 5 below show the overall trends in the proportion of tweets sent in the dominant language by day, with measured shocks marked for reference. Even from casual observation of the raw data in this manner, we can quickly see that our specific expectations derived from theory are not going to be confirmed. Instead of what we expected, what we find is that over time users of both language converge to more similar patterns of language use, with both groups increasingly using Russian over time. Thus, the directionality of the trend is not as predicted. There does, however, seem to be a responsiveness to the shocks under consideration, particularly around the resignation of Yanukovych and the beginning of the Crimea crisis 15

\footnotetext{
${ }^{15}$ One important point to note is that there is also a clear discontinuity in the Russian data that appears on June 9th and then essentially disappears around July 25th 2014. To date, we have been unable to find any significant event that would explain this particular trend in the data, and for now simply note it as additional evidence falsifying the paper's original hypotheses.
} 


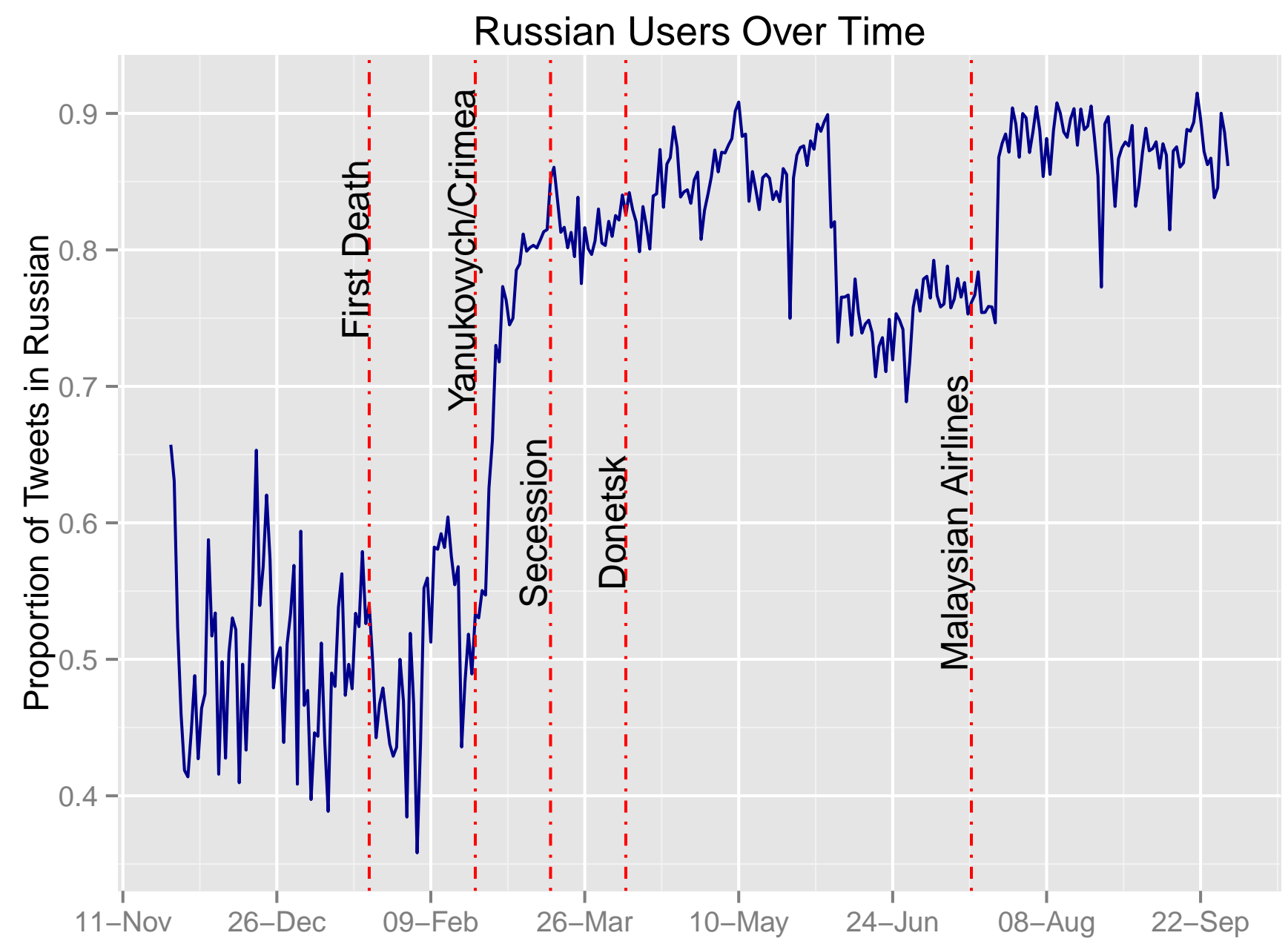

Figure 4: This figure shows the proportion of tweets written in Russian (as opposed to Ukrainian) by users whose Twitter language is Russian over time, with the key shocks under consideration marked in red with captions. 


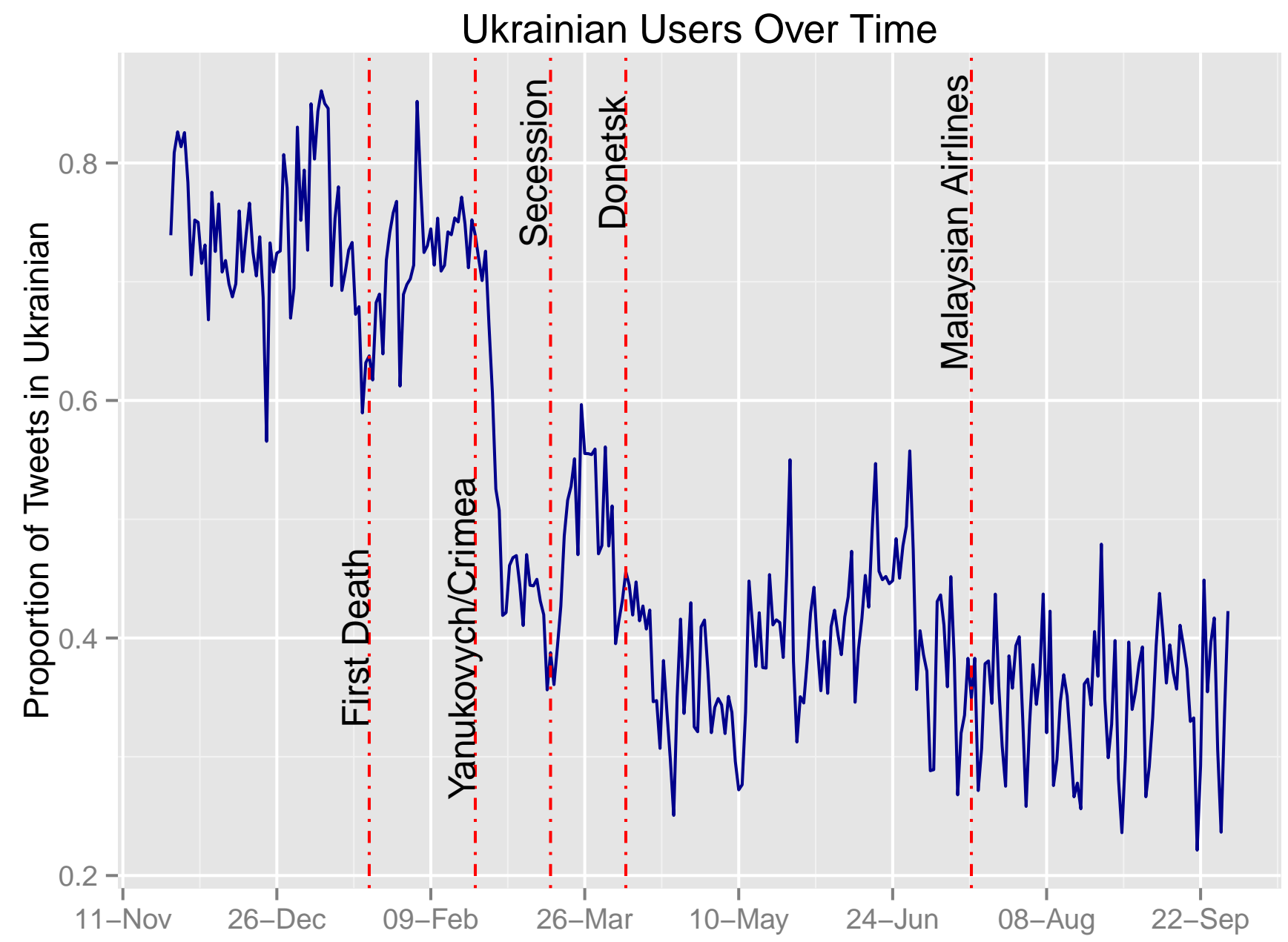

Figure 5: This figure shows the proportion of tweets written in Ukrainian (as opposed to Russian) by users whose Twitter language is Ukrainian over time, with the key shocks under consideration marked in red with captions. 
The table below reports the estimates for the $\omega$ coefficient from the intervention analysis along with p-value and standards errors. Here, for parsimony, we report only the $\omega$ coefficients and their associated statistics as these coefficient describe the impact of the shocks, which is the quantity of interest. Full model results are reported in the Appendix. 
Table 6: Results for Full Model With Multiple Shocks

\begin{tabular}{|c|c|c|c|c|}
\hline Coefficient & $\begin{array}{c}\omega \\
\text { Ukrainian Users } \\
\text { (DV: Proportion of Tweets } \\
\text { In Ukrainian) }\end{array}$ & p-value & $\begin{array}{c}\omega \\
\text { Russian Users } \\
\text { (DV: Proportion of Tweets } \\
\text { In Russian) }\end{array}$ & p-value \\
\hline $\begin{array}{l}\omega_{1} \\
\text { (First Death) }\end{array}$ & $\begin{array}{l}-.033 \\
(.013)\end{array}$ & .014 & $\begin{array}{c}.028 \\
(.016)\end{array}$ & .08 \\
\hline $\begin{array}{l}\omega_{2} \\
\text { (Yanukovych/Crimea) }\end{array}$ & $\begin{array}{l}-.185 \\
(.016)\end{array}$ & .000 & $\begin{array}{l}.192 \\
(.016)\end{array}$ & .000 \\
\hline $\begin{array}{l}\omega_{3} \\
\text { (Secession) }\end{array}$ & $\begin{array}{l}.101 \\
(.021)\end{array}$ & .000 & $\begin{array}{l}.100 \\
(.019)\end{array}$ & .000 \\
\hline $\begin{array}{l}\omega_{4} \\
\text { (Donetsk People's Republic) }\end{array}$ & $\begin{array}{l}-.088 \\
(.014)\end{array}$ & .000 & $\begin{array}{l}-.011 \\
(.016)\end{array}$ & .479 \\
\hline $\begin{array}{l}\omega_{5} \\
\text { (Malaysian Airlines }\end{array}$ & $\begin{array}{l}-.061 \\
(.009)\end{array}$ & .000 & $\begin{array}{l}.914 \\
(.009)\end{array}$ & .000 \\
\hline
\end{tabular}

What we can observe from this analysis is that although the directionality is not as predicted, we do find statistically significant changes in response to the shocks modeled in our analysis. Most notably, the coefficient for Yanukovych Fleeing/Crimea Beginning is statistically significant for both language groups at the .001 level and the coefficients are substantively large. The coefficients suggest that the sustained impact of this shock is an increase in the mean proportion of tweets in Russian of slightly under $20 \%$ for both Ukrainian and Russian users. We can see that for the Ukrainian data several other shocks are statistically significant, but again not in the predicted direction. In the Russian case, the Secession of Crimea and Malaysian Airlines shocks are statistically significant as well. For Russian users, the effect is in the predicted direction, but given our finding with regards to Ukrainian users, the interpretation of this result seems likely to be somewhat different than what we outlined above.

One potential confounder of our results is the fact that we estimate the model with retweets included as unique tweets. A potential explanation for our unexpected findings could be that users begin retweeting more Russian users following the beginning of the crisis in Crimea. In this case, these tweets would, in a sense, be being double counted, and it is not necessarily the case that the language of a tweet a user retweets is indicative of that 
user's identity. As Figures 8 and 9 below shows, however, if we remove retweets and only include original tweets in our analysis, we do not find a difference in the trends of language use. The patterns, indeed, look identical to those where retweets are included. 


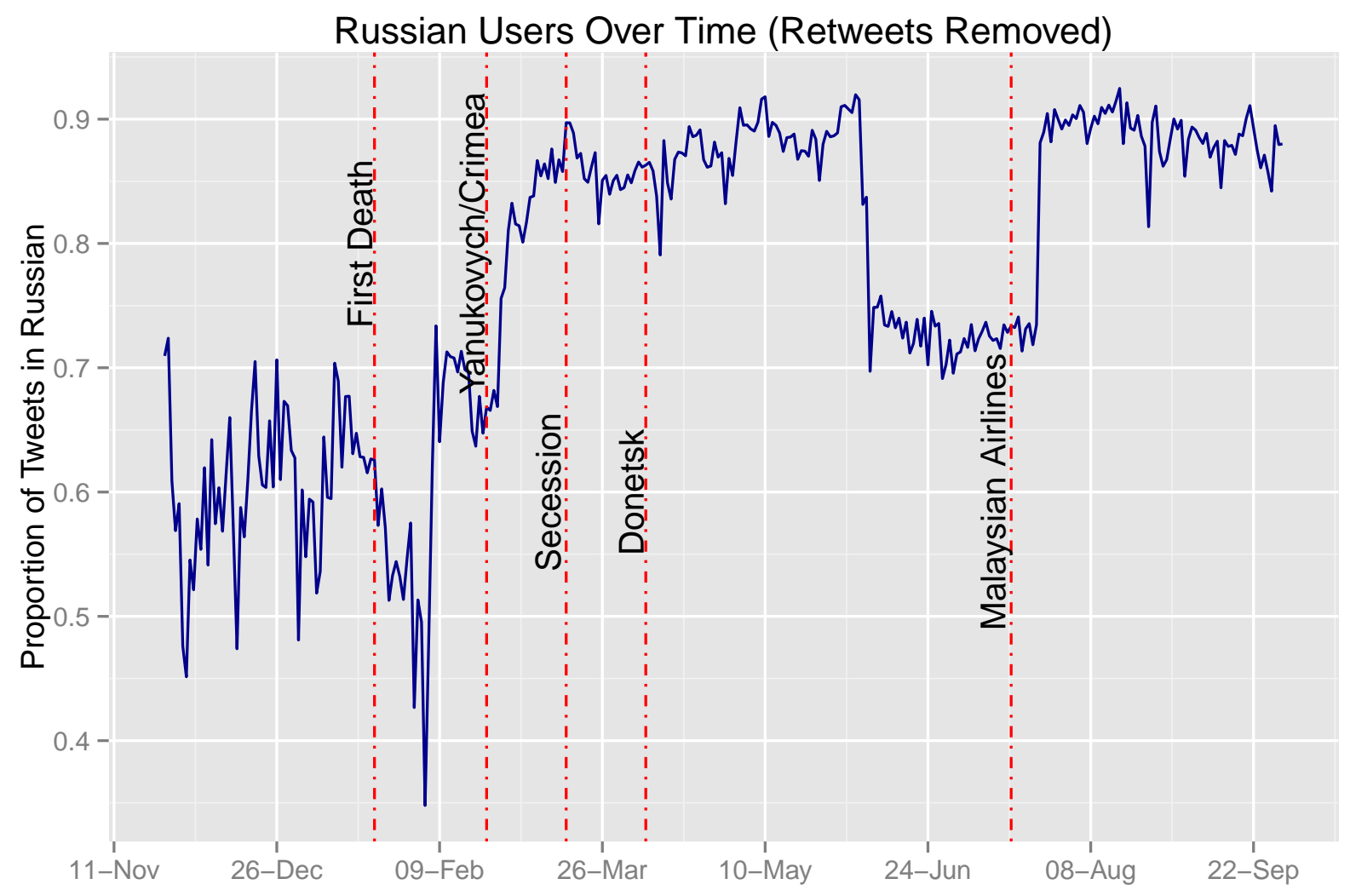

Figure 6: This figure shows the proportion of tweets written in Russian (as opposed to Ukrainian) by users whose Twitter language is Russian over time after all retweets have been removed, with the key shocks under consideration marked in red with captions. 


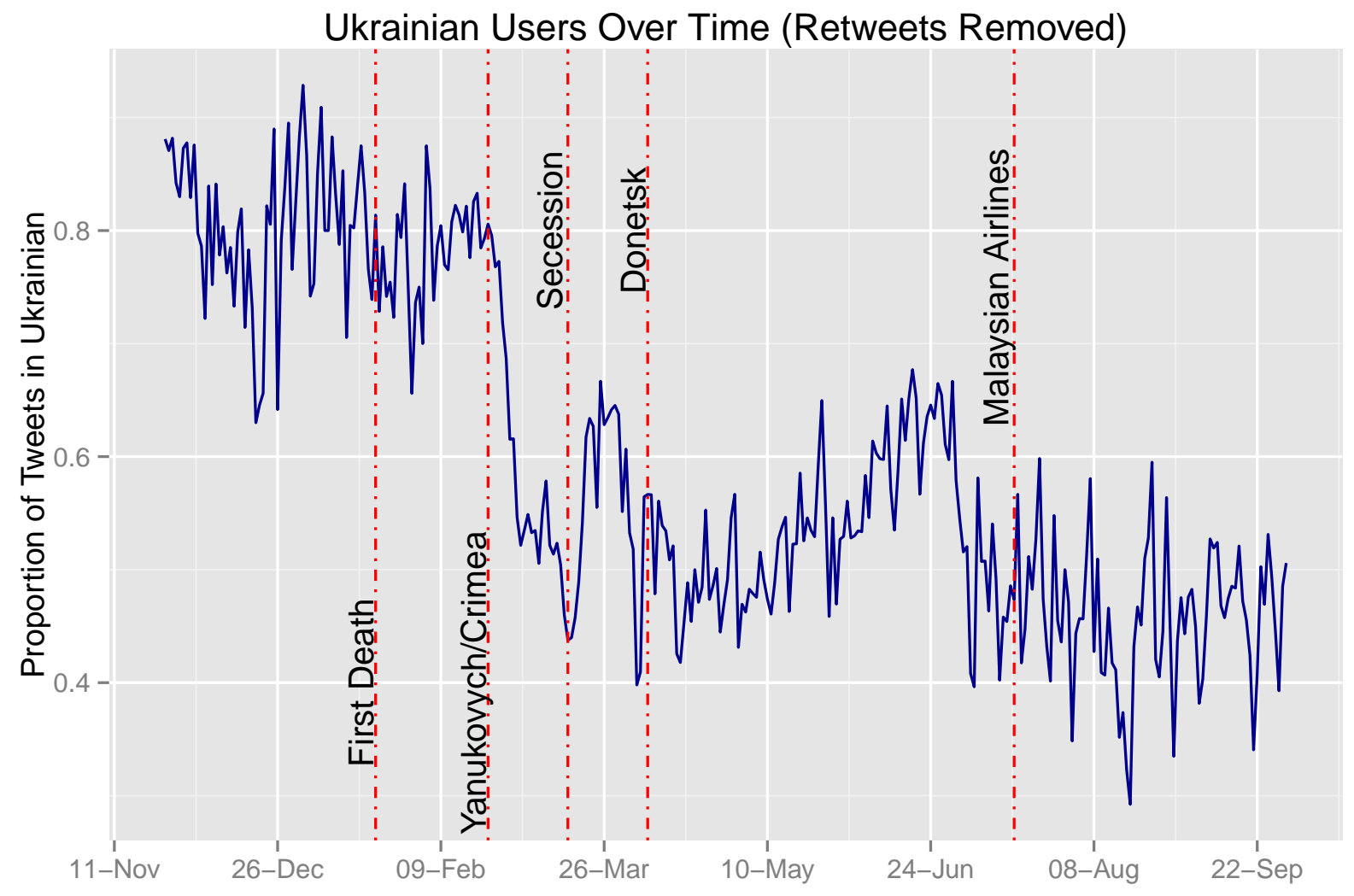

Figure 7: This figure shows the proportion of tweets written in Ukrainian (as opposed to Russian) by users whose Twitter language is Ukrainian over time after all retweets have been removed, with the key shocks under consideration marked in red with captions. 


\subsection{Interpretation}

Clearly, our overall findings do not provide consistent support for any of our hypotheses, and in fact suggest a rather different trend: both Russians and Ukrainians increased the rate at which they used Russian, particularly following the flight of Yanukovych and the onset of the Crimean crisis. There are two possible explanations for this. The first is that the theory that specific shocks will have relatively immediate impacts on the way individuals activate their ethnic identities is wrong. It is possible that while broad structural factors that are affected by these shocks influence ethnic salience, these effects accrue over a longer period of time and it is the permanent shifts in these factors - rather than exogenous shocks that may be short-term - that influence ethnic salience. The second possibility is that our operationalization of ethnic identity via language use patterns may not be capturing ethnic activation. While work on Ukraine in particular suggests that in this case this represented a plausible measure, our outcomes suggest rather that language is used not as a marker of ethnic identification, but in other ways. If this is the case, a study which used a more direct measure of ethnicity activation might bear out our expectations.

Despite not confirming the hypotheses we derived from theory, these results have identified trends in our data that are interesting in their own right. Given this set of findings, we offer several conjectures below about alternative explanations that are consistent our results. The first two of these are largely technical in nature, suggesting reasons why the particular Twitter data generation process could have produced the results we find; both of these explanations, however, we reject as unconvincing. The second two present alternative theoretical explanations and as such provide fertile grounds for future research. 


\subsection{Bots?}

One issue that is always of concern when considering social media data is the potential impact of bots. Automated bots (along with users paid to post on behalf of a government or organization) can have an important impact on the social media climate $\sqrt{16}^{16}$ To address this concern, we identifying accounts that have zero friends (that is nobody follows their accounts), as well as accounts with a friend/follower ratio that is unusually low (in other words, they follow an unusually large number of accounts relative to their number of followers). This method identified 14,494 users as potential bots, constituting approximately $11 \%$ of the users in our data set. To be clear, this number is only speculative and it is possible that some of these accounts, in fact, represent legitimate users, and it is further possible that there are other bots in the dataset that this method did not identify ${ }^{17}$

With that caveat in mind, in Figures 10 and 11 (below), we re-plot our primary analysis now removing all accounts suspected of being bots. Again, we find that the removal of these suspicious users from our dataset does not fundamentally change the patterns that we find in the rest of the paper. While it is possible that a better bot detection method would lead to use removing even more Tweets from our analysis, it is also possible that we are being overly conservative here and eliminating Tweets that we do not need to eliminate. Either way, it provides at least some preliminary confidence that our null results - and the directionality of our findings - are not being driven solely by the behavior of bots.

\footnotetext{
${ }^{16}$ See for example (Etling et al. $\mid 2010 ;$ Sidorenko 2015 ?

${ }^{17}$ This method of bot detection is laid out in more detail in Sanovich et al. (2015). In that paper, the authors not only lay out a method for identifying potential bots in social media data, but they also validate the method by qualitative inspection of approximately 900 accounts. Crucially from our perspective, they find the method to be remarkably accurate, and they do so using data from Russia. Nonetheless, readers should be aware that this type of research is very new, so all results should be interpreted with caution.
} 


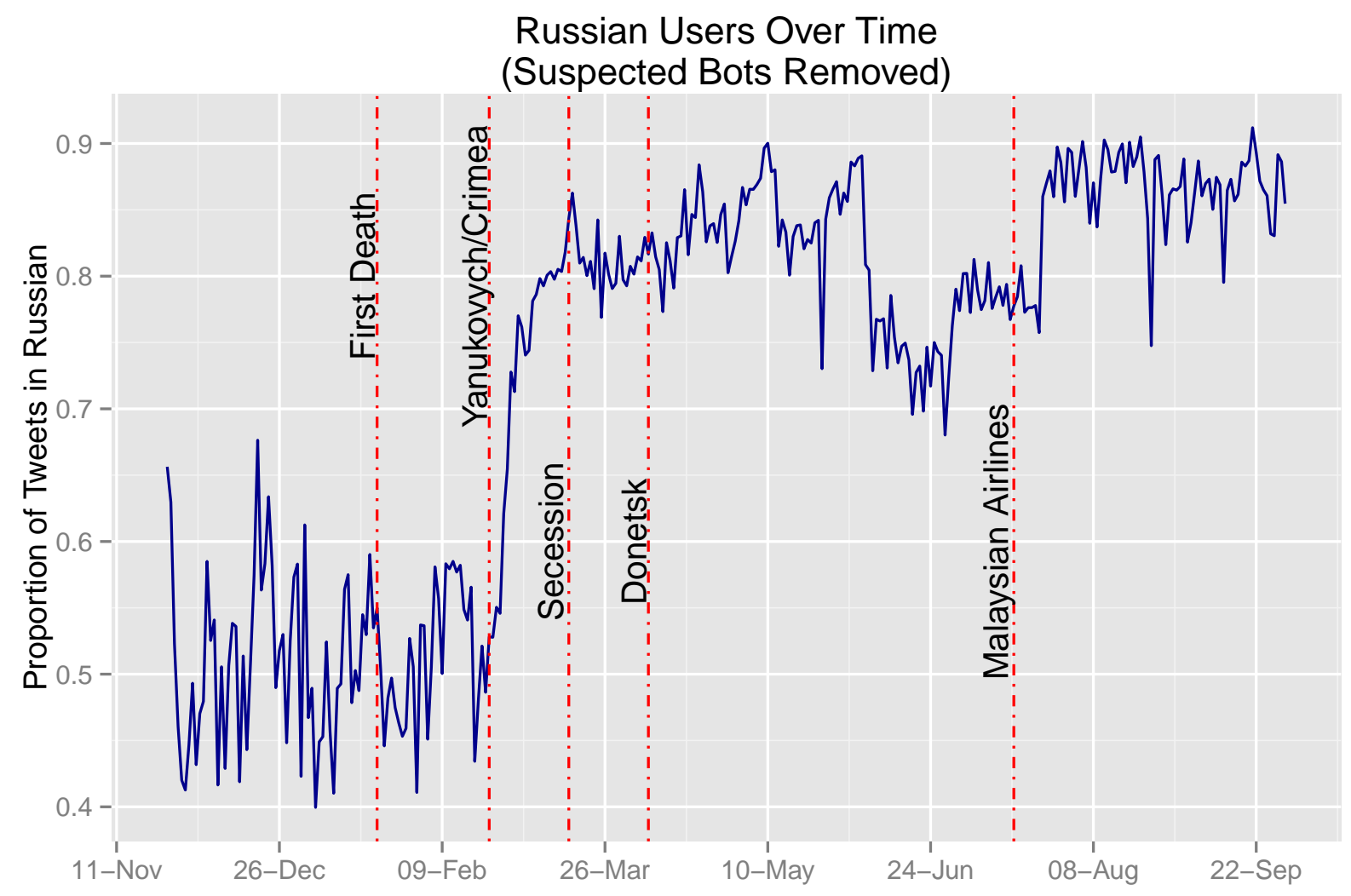

Figure 8: This figure shows the proportion of tweets written in Russian (as opposed to Ukrainian) by users whose Twitter language is Russian over time after suspected bots have been removed, with the key shocks under consideration marked in red with captions. 


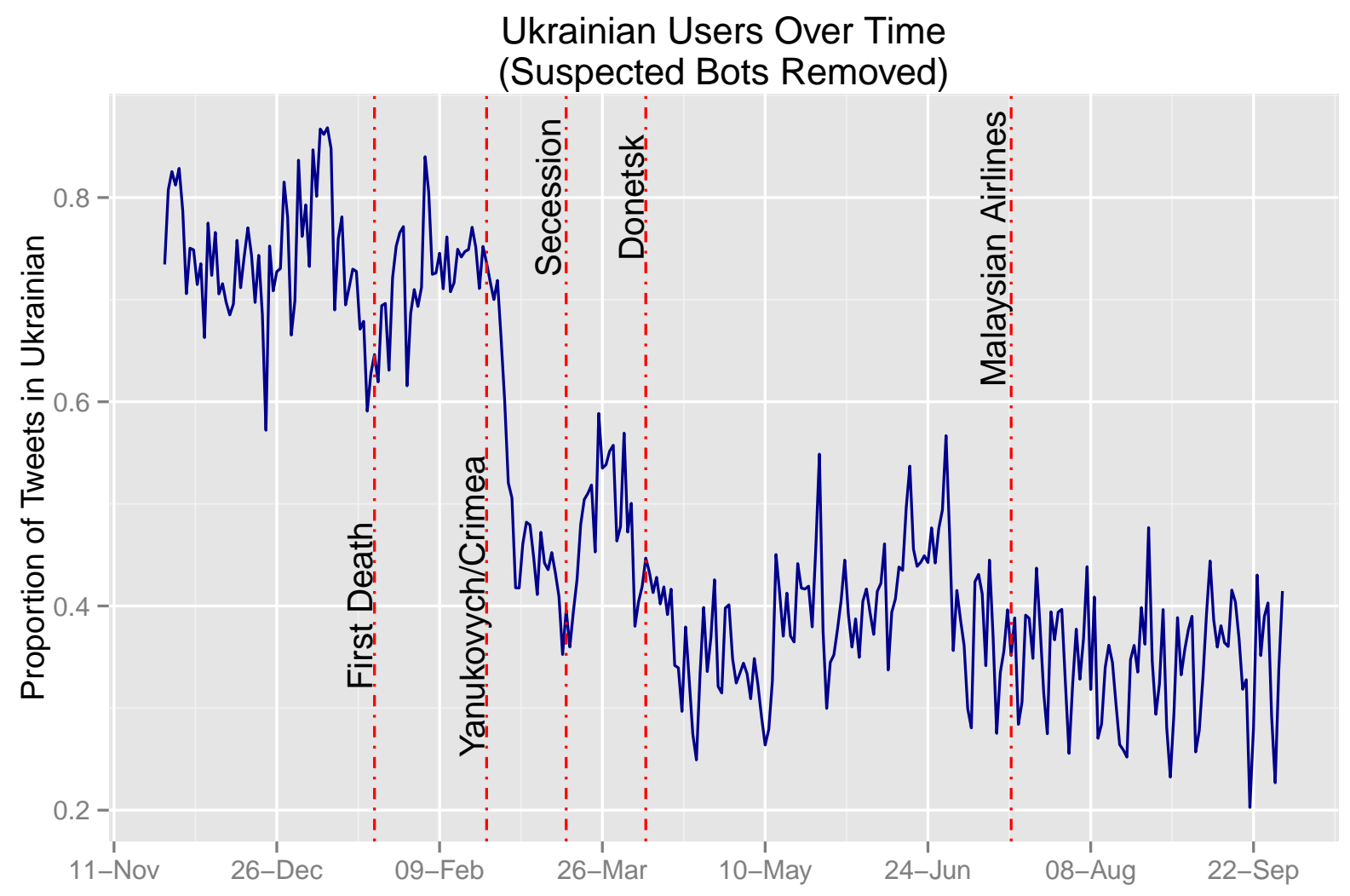

Figure 9: This figure shows the proportion of tweets written in Ukrainian (as opposed to Russian) by users whose Twitter language is Ukrainian over time after suspected bots have been removed, with the key shocks under consideration marked in red with captions. 


\subsection{Shifts in Users?}

A final potential alternative explanation for our findings is that these shifts are driven by some underlying shift in the characteristics of the data, for example in the total volume of activity or in the types of users who are tweeting. There are a few good reasons, though, to suspect that this is not the case. First, we can see that the number of tweets per day in the data is relatively stable throughout our dataset. There are some spikes, to be sure, but these spikes reequilibrate very quickly (see Figures A1 and A2 in the appendix), suggesting that they cannot explain the sustained effects that we find. While it is more plausible that, for example, different users are tweeting before and after the fall of the government, the particular structure of the effects that we find suggests that it is unlikely that this explains all of our findings. More specfically, for this explanation to explain the entire shift towards a great prevalence of Russian language usage without an overall increase in the volume of tweets, we must believe that some relatively substantial group from the early part of the data set abruptly stopped tweeting at or around our shock point while simultaneously a new group of users of approximately the same volume took their place. Further, because these effects are sustained, we must believe that the type of users who opt out just at the cut point never rejoin the dataset. While it is certainly possible that some of this is happening and driving part of the effect, the effect we identify is substantively large enough to suggest that there is also a shift in the behavior of the types of users participating before the shock.

One feature of our data generating process is that as time passed, keywords were added to the collection criteria in order to maximize the politically relevant tweets in the dataset (see discussion above in Section 4.2). This is not a design flaw, but rather ensure that as what people are talking about in relation to events on the ground changes, the collection continues to containt relevant data. 18 A possible concern could be that these shifts occur

\footnotetext{
${ }^{18}$ To reiterate, the data for this project were collected in real time through the Twitter Streaming API, not purchased after the fact as part of a historical archive (i.e., from an organization such as GNIP). As an illustration of why this is simply a feature of the data collection process and not a design flaw, consider
} 
in response not to events on the ground, but to changes to the keywords on which we are collecting. Initial analyses, however, suggest that this is unlikely. Figure 10 below shows the volume of tweets over time with markers for when new keywords were added to our collection criteria. What we can see in this figure is that there is no obvious relationship between the addition of new keywords and the behavior of our data. Indeed, most of the spikes in activity in our data precede our addition of keywords, which is sensible given that we are attempting to add new words in response to changes in events on the ground. This suggests, however, that our principle findings in the paper are therefore not simply artifacts of the data generating process.

the downing of the Malaysian airliner MH17. The hashtag \#MH17 was added to the dataset of course after the plane was shot down - it is impossible to think of an original research design that would have included \#MH17 in the collection from the date of original data collection. 
Figure 10

Tweets per day by language

100000 vertical bars are keyword additions

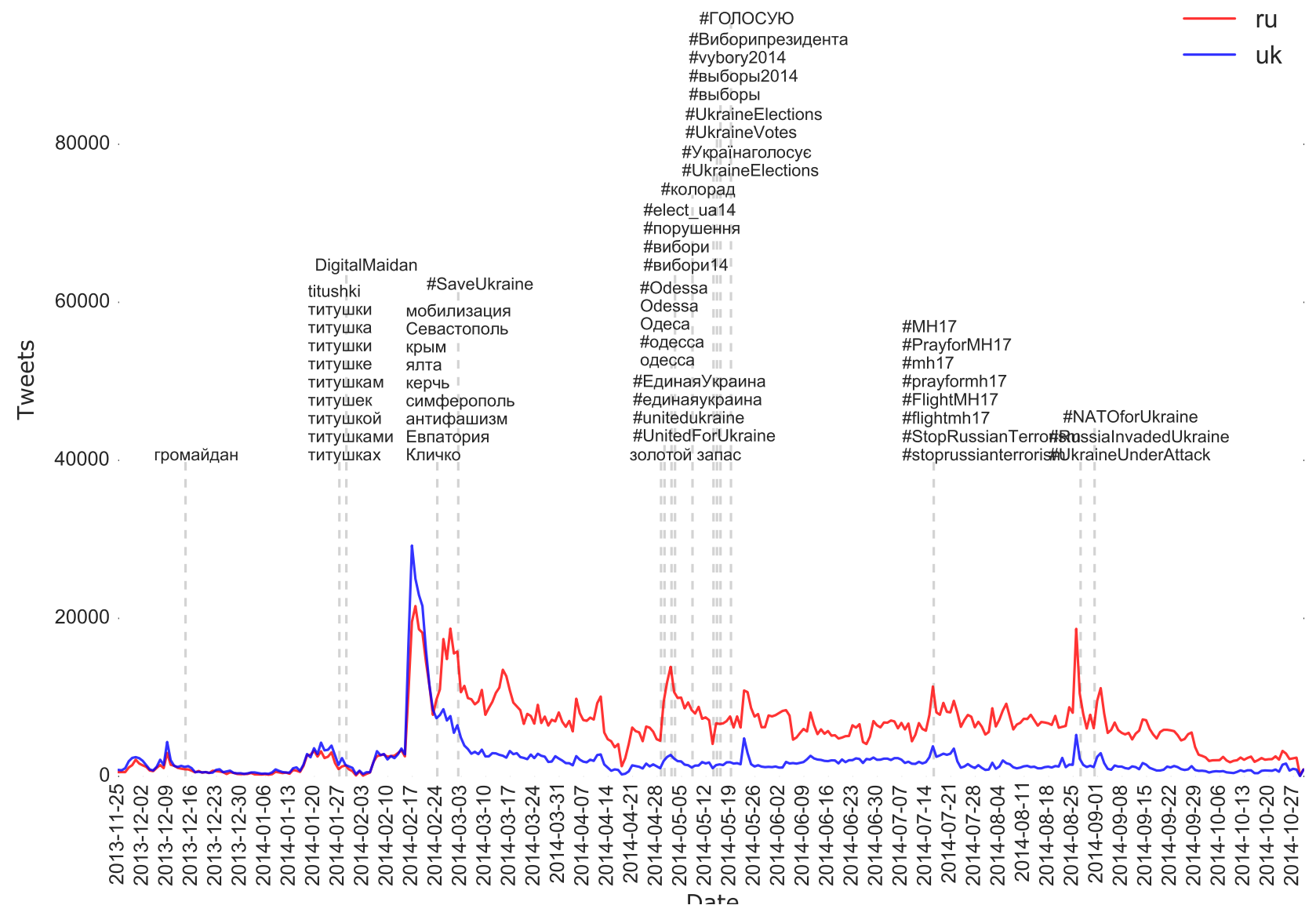




\subsection{Alternative Explanation: Common Language Communication}

If technical reasons can not explain our findings, then it seems worthwhile to consider what sort alternate theoretical accounts might be consistent with our unexpected finding that both Ukrainian-preferred and Russian-preferred users began tweeting more frequently in Russia. To be clear, as we are now theorizing after the fact, this exercise should be considered one of theory-building and not hypothesis testing. Nevertheless, it can provide useful suggestions for guiding future research.

One potential alternative explanation could stem from the fact that Russian is the language spoken as either first or second language by the largest number of people in the country, and therefore is best suited to serve as a language of "national communication" when necessary. Practically everybody in Ukraine speaks, or minimally reads, Russian to some degree. We might therefore explain the shift we see to additional Russian usage on Twitter by both those who generally prefer Russian and those who prefer Ukrainian as a reversion to the most common form of communication in the country during a period of crisis. If ethnicity is not a critical cleavage here, perhaps instead people are simply making linguistic choices that maximize their communication with the largest number of people in the country. This, however, fails to explain why Russian users were tweeting so much in Ukrainian during the early days of the protests ${ }^{19}$

\subsection{Alternative Explanation: Situational/Strategic Communication}

Perhaps a more likely explanation is that users in a highly bilingual context strategically alter their language use patterns in response to context in a way that is not about ethnicity. Note that we find the most dramatic shift in language usage - in the direction of increased

\footnotetext{
${ }^{19}$ That being said, it may have been that the nature of communication around the \#Euromaidan protests has a Ukrainian component whereby Tweeting in Ukrainian was one way to show support for the protests, and in particular for Russians to show support for the protest, i.e., that the protest was against Yanukovych and corruption, and not a Russian vs. Ukrainian split.
} 
Russian usage - right as Russia (the country) becomes an increasingly important player in the crisis. Perhaps individuals, particularly on a public platform like Twitter, will employ the language which makes them best able to communicate with the groups for whom these events are salient, or which provides them with some strategic advantage. This would fit with descriptive evidence from previous protests, where social media use in English seemed to be used to strategically target external actors in order to garner increased international suppert. In the Ukrainian case, perhaps once Russia becomes a more central player, users strategically optimize the impact of their tweets by using Russian rather than Ukrainian. This theory has the further advantage of explaining well why Russians might have used Ukrainian in higher numbers during the protests. While the situation was primarily a domestic one, Ukrainian represented a language which could be directed at the actors of interest. Discussing domestic issues in Ukrainian can be strategically advantageous, whereas doing so if you want your communication to be more broadly received is not. Importantly, tweets in English are excluded from this analysis. If we wish to test this type of argument in the future, it may be sensible to explore in more detail the role of English language Tweets.

\section{Conclusion and Future Work}

This paper set out to explore at a fine grained level the relationship between certain types of shocks and the activation of ethnic identity. We hypothesized that shocks that contributed to the larger-scale, more macro phenomena that have been shown to relate broadly to ethnic salience would elicit an activation response on the part of individuals. Using Twitter data allowed us to do this based on individual's actual behavior in real time, rather than on self-report or behavior as primed in the lab.

Our results did not provide support for our hypotheses, and instead seem to suggest that perhaps the proxy that we used to measure ethnic activation, proportion of tweets in a 
user's dominant language, was not an appropriate proxy for ethnic identity activation. The question of what precise phenomenon will tend to elicit the activation of ethnic identities is still an important one, and there are several ways that we hope to move this work forward.

One direction would be to develop a measure of ethnic salience that relies not on the language of the tweet but rather on the content of the tweet. The advantage of relying on language usage is that it can be estimated very precisely; the disadvantage is that we have no guarantee that a Ukrainian who uses Ukrainian instead of Russian is doing so because she feels a heightened sense of ethnic identity. Analysis of the context of tweets, i.e., the text, can come closer to ensuring that we are actually measuring something that represents increased ethnic salience. The difficulty of turning to the content of tweets is that it requires us to develop a method to identify ethnic salience within text. Nevertheless, this seems an obvious next step in the research agenda.

However, the trends identified in our data are potentially important in and of themselves as they suggest interesting, strategic approaches to language use on the part of social media users. While this is quite a different question from the one we set out to address, the finding that shifts in patterns of language use on social media are homogenous across Ukrainian and Russian-preferring Twitter users, and respond in key ways to critical events on the ground, is a finding that deserves additional attention. An important step here will be to consider the role of English. While it was essential to exclude English from our analysis here because it is unclear how to interpret this as an aspect of ethnic identity activation, we can theorize about the role English might play as a language of strategic communication. Indeed, early analysis suggests that shifts in Ukrainian users' language use patterns may actually be shifts in the proportion of tweets in Russian versus English, rather than in Russian versus Ukrainian. Moving forward, more should be done to understand the exact linguistic behavior that we are observing. Further, content coding and topic modeling approaches will allow us to explore whether the shifts we see represent only linguistic shifts, or also important topical shifts as 
well.

For both of these avenues of continued work, it is also important to move beyond the aggregate level data to consider within subject variation. This will allow us to look at how specific users change their behavior over time, and to consider alternative explanations for aggregate trends, such as changes in the types of users tweeting at any given time.

While we do not find evidence here to support our initial hypotheses, we have nonetheless uncovered interesting trends which pose new questions both about our original topic of interest, and about a newer topic: the way individuals use language strategically during crisis on social media platforms. Future work should address both the main topic of this essay and the question of strategic use of language as interesting, but likley separate, areas of study. 


\section{A Appendix}

\section{A.1 Descriptive Statistics}

Table A.1

\begin{tabular}{|c|c|c|}
\hline $\begin{array}{c}\text { Total Tweets } \\
\text { (Data from November 25, 2013 } \\
\text { to October 30th, 2014) }\end{array}$ & $\begin{array}{c}\text { Ukrainian } \\
\text { Language Users }\end{array}$ & $\begin{array}{c}\text { Ruan } \\
\text { Language Users }\end{array}$ \\
\hline $\begin{array}{c}\text { Standard Deviation of } \\
\text { Proportion of Tweets } \\
\text { in Dominant Language } \\
\text { By Day }\end{array}$ & 550,380 & $3,071,580$ \\
\hline $\begin{array}{c}\text { Minimum Proportion of } \\
\text { Tweets in Dominant } \\
\text { Language By Day }\end{array}$ & .17 & .16 \\
\hline $\begin{array}{c}\text { Maximum Proportion of } \\
\text { Tweets in Dominant } \\
\text { Language By Day }\end{array}$ & .22 & .36 \\
\hline
\end{tabular}


A.2 Keywords and Hashtags Used for Data Collection 
Table A.2: Ukraine Key Words and Hashtags

\begin{tabular}{|c|c|c|c|}
\hline Date Added & Key Word & Date Added & Key Word \\
\hline 9/1/2014 0:00:00 & \#NATOforUkraine & 1/28/2014 0:00:00 & титушке \\
\hline 8/28/2014 0:00:00 & \#RussiaInvadedUkraine & 1/28/2014 0:00:00 & титушкам \\
\hline 8/28/2014 0:00:00 & \#UkraineUnderAttack & 1/28/2014 0:00:00 & титушек \\
\hline 7/17/2014 21:15:20 & \#stoprussianterrorism & 1/28/2014 0:00:00 & титушкой \\
\hline 7/17/2014 21:15:04 & \#StopRussianTerrorism & 1/28/2014 0:00:00 & титушками \\
\hline $7 / 17 / 2014$ 20:28:20 & \#flightmh17 & 1/28/2014 0:00:00 & титушках \\
\hline $7 / 17 / 2014$ 20:28:12 & \#FlightMH17 & 12/15/2013 0:00:00 & громайдан \\
\hline 7/17/2014 20:09:01 & \#prayformh17 & None & kyiv \\
\hline 7/17/2014 20:08:38 & $\# \operatorname{mh} 17$ & None & kiev \\
\hline 7/17/2014 20:01:52 & \#PrayforMH17 & None & ukraine \\
\hline 7/17/2014 20:01:29 & \#MH17 & None & євромайдан \\
\hline 5/20/2014 20:39:37 & \#ГОЛОСУЮ & None & euromadan \\
\hline $5 / 17 / 2014$ 4:24:20 & \#выборы & None & Euromaidan \\
\hline 5/17/2014 4:24:03 & \#vybory2014 & None & Euromaydan \\
\hline $5 / 17 / 2014$ 4:23:49 & \#выборы2014 & None & Евромайдан \\
\hline $5 / 17 / 20144: 23: 32$ & \#Виборипрезидента & None & Евромайдан \\
\hline $5 / 16 / 2014$ 18:53:53 & \#UkraineVotes & None & евромайдан \\
\hline $5 / 16 / 2014$ 18:53:06 & \#UkraineElections & None & євромайдан \\
\hline 5/15/2014 19:03:16 & \#UkraineElections & None & Євромайдан \\
\hline $5 / 15 / 2014$ 19:02:53 & \#Українаголосує & None & ЄвроМайдан \\
\hline 5/9/2014 17:46:14 & \#колорад & None & Майдан \\
\hline 5/4/2014 18:20:41 & \#вибори14 & None & Європа \\
\hline $5 / 4 / 2014$ 18:20:33 & \#вибори & None & Batkivshchyna \\
\hline 5/4/2014 18:20:24 & \#порушення & None & тимошенко \\
\hline 5/4/2014 18:20:18 & \#elect_ua14 & None & яценюк \\
\hline $5 / 3 / 20143: 23: 16$ & одесса & None & кличко \\
\hline $5 / 3 / 2014$ 3:23:02 & \#одесса & None & УДАР \\
\hline $5 / 3 / 20143: 20: 34$ & Одеса & None & кабмин \\
\hline $5 / 3 / 2014$ 3:20:20 & Odessa & None & беркут \\
\hline $5 / 3 / 2014$ 3:19:41 & \#Odessa & None & янукович \\
\hline 5/1/2014 17:16:52 & \#единаяукраина & None & азаров \\
\hline 5/1/2014 17:16:41 & \#ЕдинаяУкраина & None & Майдан \\
\hline $5 / 1 / 2014$ 17:16:33 & \#UnitedForUkraine & None & революция \\
\hline 5/1/2014 17:16:11 & \#unitedukraine & None & революція \\
\hline 4/30/2014 22:09:43 & золотой запас & None & StopEU \\
\hline 3/3/2014 0:00:00 & \#SaveUkraine & None & СтопЕС \\
\hline 2/25/2014 0:00:00 & мобилизация & None & Міліція \\
\hline 2/25/2014 0:00:00 & Севастополь & None & Беркут \\
\hline 2/25/2014 0:00:00 & крым & None & euromaydan \\
\hline $2 / 25 / 2014$ 0:00:00 & ялта & None & evromaidan \\
\hline $2 / 25 / 2014$ 0:00:00 & керчь & None & maidan \\
\hline $2 / 25 / 2014$ 0:00:00 & симферополь & None & Berkut \\
\hline $2 / 25 / 2014$ 0:00:00 & антифашизм & None & Буркут \\
\hline 2/25/2014 0:00:00 & Евпатория & None & UkraineProtests \\
\hline 2/25/2014 0:00:00 & Кличко & None & prayforukraine \\
\hline 1/30/2014 0:00:00 & DigitalMaidan & None & Таможенный \\
\hline 1/28/2014 0:00:00 & titushki & None & йолка \\
\hline 1/28/2014 0:00:00 & титушки & None & ёлка \\
\hline 1/28/2014 0:00:00 & титушка & None & стопмайдан \\
\hline 1/28/2014 0:00:00 & титушки & None & антимайдан \\
\hline
\end{tabular}




\section{A.3 Graphs of Total Tweet Volume Over Time}

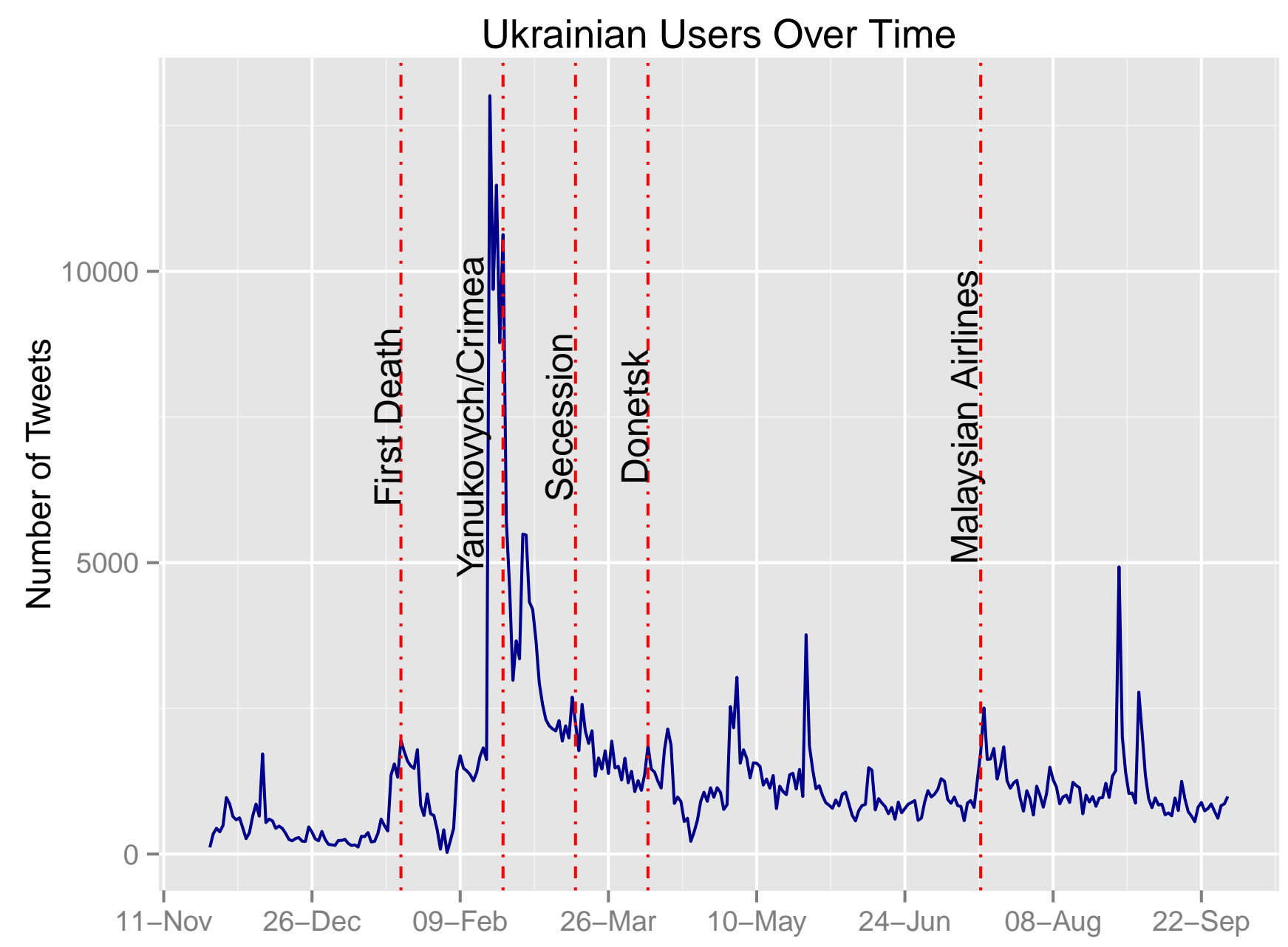

Figure A.1: This figure shows the volume of tweets, that is the number of tweets sent, for Ukrainian users over time, with key shocks marked in red with captions. 


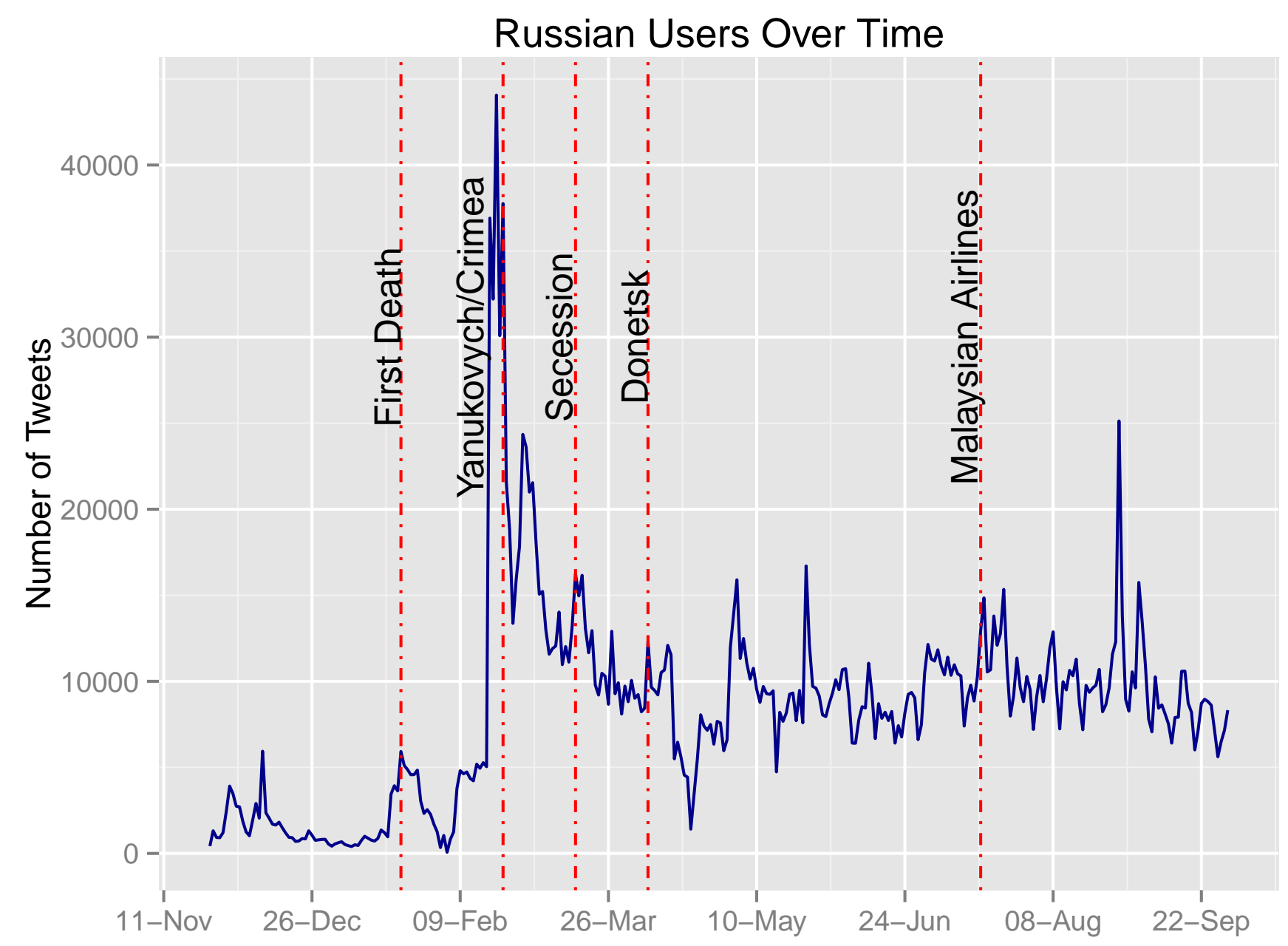

Figure A.2: This figure shows the volume of tweets, that is the number of tweets sent, for Russian users over time, with key shocks marked in red with captions. 


\section{A.4 Full Model Results}

Table A.3

\begin{tabular}{|c|c|c|c|c|}
\hline Coefficient & $\begin{array}{c}\omega \\
\text { Ukrainian Users } \\
\text { (DV: Proportion of Tweets } \\
\text { In Ukrainian) }\end{array}$ & p-value & $\begin{array}{c}\omega \\
\text { Russian Users } \\
\text { (DV: Proportion of Tweets } \\
\text { In Russian) }\end{array}$ & p-value \\
\hline $\begin{array}{l}\omega_{1} \\
\text { (First Death) }\end{array}$ & $\begin{array}{l}-.033 \\
(.013)\end{array}$ & .014 & $\begin{array}{l}.028 \\
(.016)\end{array}$ & .08 \\
\hline $\begin{array}{l}\omega_{2} \\
\text { (Yanukovych/Crimea) }\end{array}$ & $\begin{array}{l}-.185 \\
(.016)\end{array}$ & .000 & $\begin{array}{l}.192 \\
(.016)\end{array}$ & .000 \\
\hline $\begin{array}{l}\omega_{3} \\
\text { (Secession) }\end{array}$ & $\begin{array}{l}-.038 \\
(.017)\end{array}$ & .03 & $\begin{array}{l}.101 \\
(.021)\end{array}$ & .000 \\
\hline $\begin{array}{l}\omega_{4} \\
\text { (Donetsk People's Republic) }\end{array}$ & $\begin{array}{l}-.088 \\
(.014)\end{array}$ & .000 & $\begin{array}{l}-.011 \\
(.016)\end{array}$ & .479 \\
\hline $\begin{array}{l}\omega_{5} \\
\text { (Malaysian Airlines }\end{array}$ & $\begin{array}{l}-.061 \\
(.009)\end{array}$ & .000 & $\begin{array}{l}.021 \\
(.014)\end{array}$ & .123 \\
\hline$\phi_{1}$ & $\begin{array}{l}.214 \\
(.012)\end{array}$ & .000 & $\begin{array}{l}.914 \\
(.009)\end{array}$ & .000 \\
\hline$\phi_{2}$ & $\begin{array}{l}.101 \\
(.012)\end{array}$ & .000 & & \\
\hline$\phi_{3}$ & $\begin{array}{l}.084 \\
(.012) \\
\end{array}$ & .000 & & \\
\hline$\theta_{1}$ & & & $\begin{array}{l}.393 \\
(.048)\end{array}$ & .000 \\
\hline Intercept & $\begin{array}{l}.742 \\
(.008)\end{array}$ & .000 & $\begin{array}{c}.501 \\
(.001)\end{array}$ & .000 \\
\hline $\begin{array}{l}\text { RMSE } \\
\text { AIC } \\
\text { BIC }\end{array}$ & $\begin{array}{c}.171 \\
-5021.55 \\
-4952.73\end{array}$ & & $\begin{array}{c}.089 \\
-14647.28 \\
-14585.16 \\
\end{array}$ & \\
\hline
\end{tabular}

Standard errors in parentheses 
A.5 Visualizations of Model Fit

Figure A.3

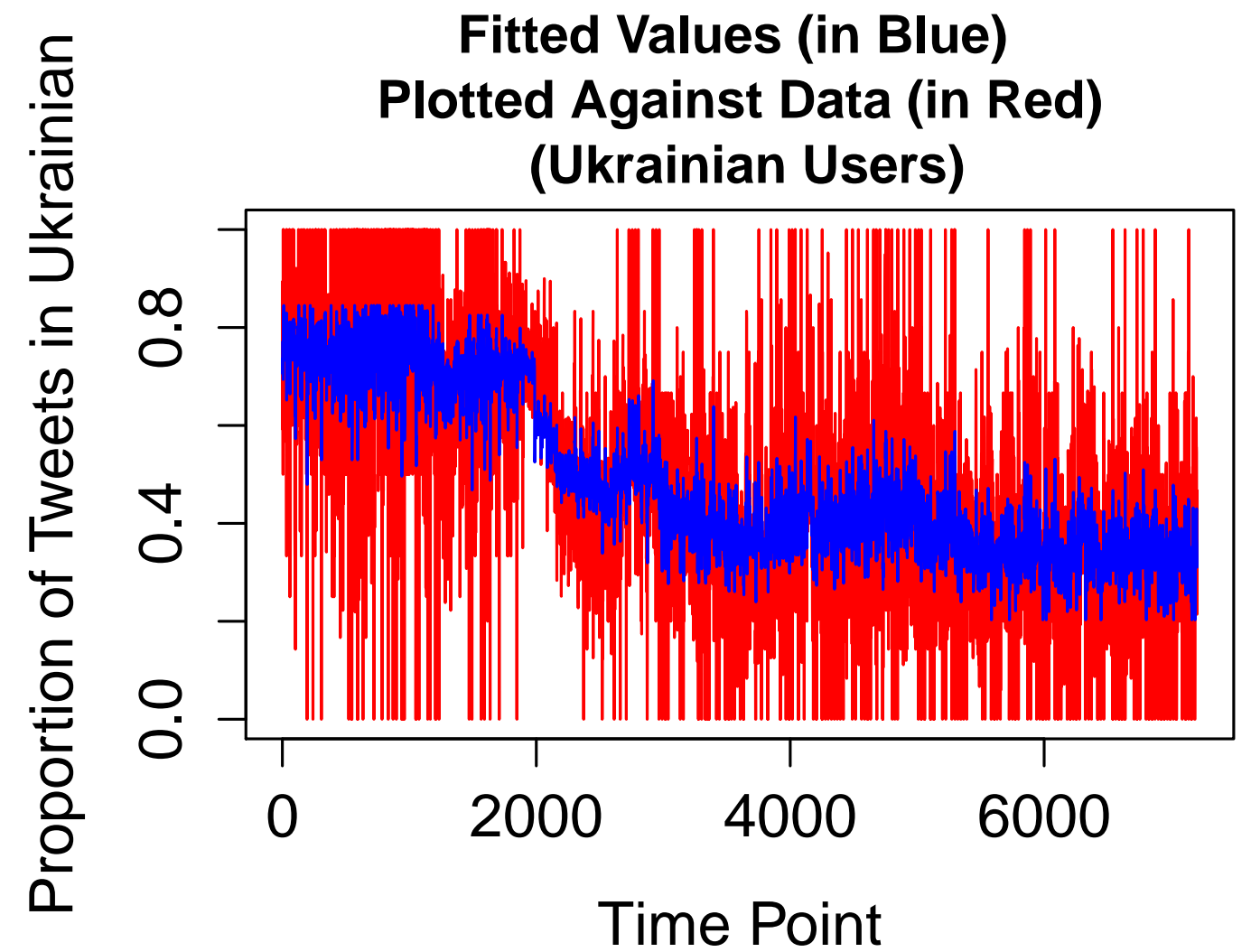


Figure A.4

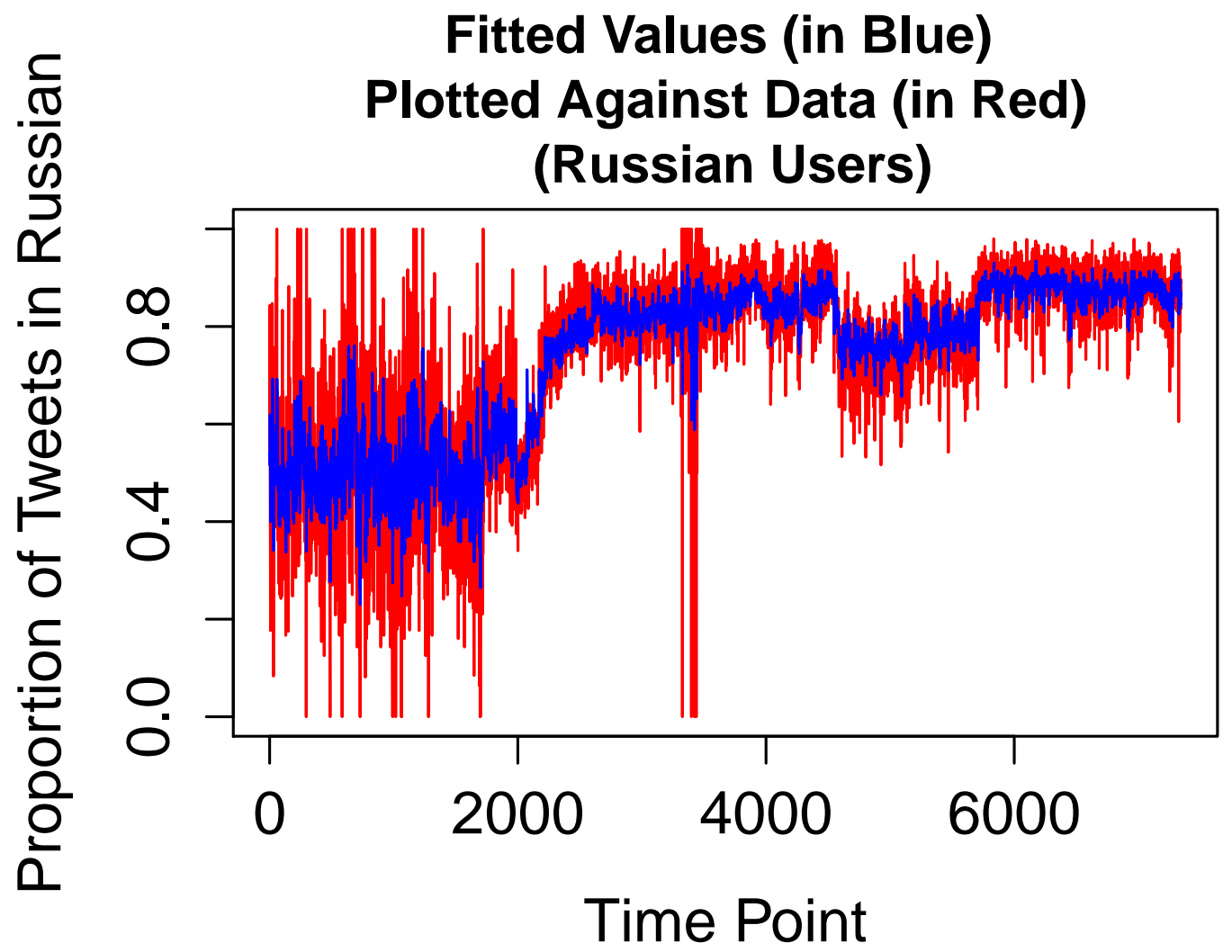




\section{References}

Arel, D. 1995. Ukraine: A Temptation of a Nationalizing State. In: Tismaneanu, V. (ed), Political Culture and Civil Society in Russia and the New States of Eurasia. London: M.E. Sharp.

Arel, D. 2002. Interpreting nationality and language in the 2001 Ukrainian Census. PostSoviet Affairs, 18(3), 213-249.

Bannon, A., Miguel, E., \& Posner, D. 2004. Sources of Ethnic Identification in Africa. Afrobarometer Working Papers.

Barrington, L., \& Herron, E. 2004. One Ukraine or Many? Regionalism in Ukraine and Its Political Consequences. Nationalities Papers, 32(1), 53-86.

Bhavani, R., \& Miodownik, D. 2009. Ethnic Polartization, Ethnic Salience and Civil War. Journal of Conflict Resolution, 53(1), 30-49.

Bohdanova, Tetyana. 2014. Unexpected Revolution: The Role of Social Media in Ukraine's Euromaidan Uprising. European View.

Box, G.E.P., \& Tiao, G.C. 1975. Intervention Analysis With Applications to Economic and Environmental Problems. Journal of the American Statistical Association, 70(349), 70-79.

Caselli, F., \& Coleman, W. J. 2013. On the Theory of Ethnic Conflict. Journal of the European Economic Association, 11, 161-192.

Chandra, K. 2004. Why Ethnic Parties Succeed: Patronage and Ethnic Head Counts in India. Cambridge University Press.

Chandra, K. 2012. Constructivist Theories of Ethnic Conflict. Oxford University Press. 
Constant, A., Kahanec, M., \& Zimmerman, K. 2011. The Russian-Ukrainian Political Divide. Eastern European Economics, 49(6), 97-109.

Constant, A., Kahanec, M., \& Zimmerman, K. 2012. The Russian-Ukrainian Earnings Divide. Economics of Transition, 20(1), 1-35.

Esteban, J., Mayoral, L., \& Ray, D. 2012. Ethnicity and Conflict: An Empirical Study. American Economic Review, 102(4), 1310-1342.

Etling, Bruce, Alexanyan, Karina, Kelly, John, Faris, Robert, Palfrey, John G., \& Gasser, Urs. 2010. Public Discourse in the Russian Blogosphere: Mapping RuNet Politics and Mobilization. SSRN Scholarly Paper. http://papers.ssrn.com/abstract=1698344.

Evans, Geoffrey, \& Need, Ariana. 2002. Explaining ethnic polarization over attitudes towards minority rights in Eastern Europe: a multilevel analysis. Social Science Research, 31, 653680.

Fearon, James, \& Laitin, David. 2003. Ethnicity, Insurgency, and Civil War. The American Political Science Review, 97(1), 75-90.

Fisher, Max. 2014. This is the one map you need to understand Ukraine's crisis. Monkey Cage Blog of the Washington Post.

Frye, T. 2014. What do Ukraine Voters Want? A Survey Experiment on Candidate Language, Ethnicity and Policy Orientation. Available at SSRN: http://ssrn.com/abstract=2477440.

Gagnon, V.P. 2006. The Myth of Ethnic War: Serbia and Croatian in the 1990s. Cornell University Press. 
Habyarimana, J., Humphreys, M., Posner, D., \& Weinstein, J. 2007. Why Does Ethnic Diversity Undermine Public Goods Provision? American Political Science Review, 101(4), 709-725.

Horowitz, D. 1985. Ethnic Groups in Conflict. University of California Press.

Ivanova, O. 2013. Bilingualism in Ukraine: Defining Attitudes to Ukrainian and Russian Through Geographical and Generational Variations in Language Patterns. Sociolinguistic Studies, 7(3), 249-272.

Kulyk, V. 2006. Constructing Common Sense: Language and Ethnicity in Ukrainian Public Discourse. Ethnic and Racial Studies, 29(2), 281-314.

Minchenko, Olga. 2013. [Which websites do Ukrainians use?]. Watcher, November. Available at http://watcher.com.ua/2013/11/19/ yakymy-saytamy-korystuyutsya-ukrayintsi/.

Oakes, PJ. 1987. The Salience of Social Categories. In: Turner, J.C. (ed), Rediscovering the Social Group. Oxford: Basil Blackwood.

Oberschall, A. 2000. The Manipulation of Ethnicity: From Ethnic Cooperation to Violence and War in Yugoslavia. Ethnic and Racial Studies, 23(6), 982-1001.

Posner, D. 2004. The Political Salience of Cultural Difference: Why Chewas and Tumbukas are allies in Zambie and Adversaries in Malawi. American Political Science Review, 98(4), $529-545$.

Sanovich, Sergey, Stukal, Denis, Penfold-Brown, Duncan, \& Tucker, Joshua. 2015. Turning the Virtual Tables: Government Strategies for Addressing Online Opposition with an Application to Russia. Paper presented at the 2015 Annual Conference of the International Society of New Institutional Economics. 
Sidorenko, Alexey. 2015. Russia: Major Search Engine Closes Its Blog Rating. Global Voices, November. http://globalvoicesonline.org/2009/11/06/russia-major-search-enginecloses-its-blog-rating/.

Sikorska, Olena. 2014. Yandex Report: Twitter Usage in Ukraine. Digital EastFactor, November. Available at http://www.digitaleastfactor.com/ yandex-report-twitter-usage-ukraine/.

Stryker, S. 1968. Identity Salience and Role Performance. Journal of Marriage and the Family, 30, 538-544.

Stryker, S., \& Burke, P. 2000. The Past, Present and Future of an Identity Theory. Social Psychology Quarterly, 63(4), 284-297.

Toal, G., \& Dahlman, C. 2011. Bosnia Remade: Ethnic Cleansing and its Reversal. Oxford University Press.

Tsay, R., \& Tiao, G.C. 1984. Consistent Estimates of Autoregressive Parameters and Extended Sample Autocorrelation Function for Stationary and Nonstationary ARMA Models. Journal of the American Statistical Association, 78(385), 84-96.

Waters, M. 1999. Black Identities: West Indian Immigrant Dreams and American Realities. Russell Sage Foundation.

Wilson, A. 2002. Elements of a Theory of Ukrainian Ethno-national Identities. Nations and Nationalism, 8(1), 31-54.

Wilson, S. 2014. Networks, Protest and Euromaidan: Social Media Networks and the Ukrainian Protests. Paper Presented at the 2014 ASSEES Annual Meeting. 